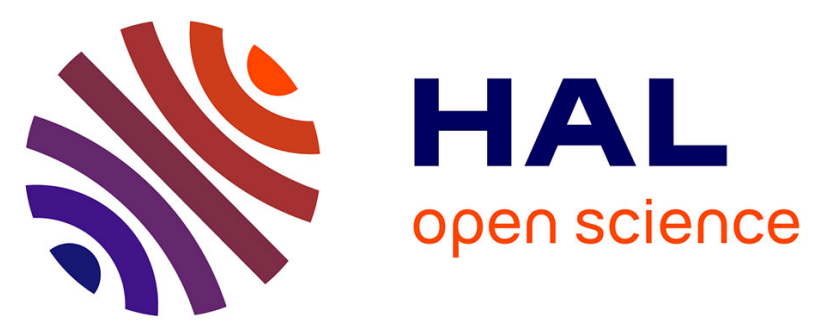

\title{
A CEP Peptide Receptor-Like Kinase Regulates Auxin Biosynthesis and Ethylene Signaling to Coordinate Root Growth and Symbiotic Nodulation in Medicago truncatula
}

Fugui Zhu, Jie Deng, Hong Chen, Peng Liu, Lihua Zheng, Qinyi Ye, Rui Li, Mathias Brault, Jiangqi Wen, Florian Frugier, et al.

\section{To cite this version:}

Fugui Zhu, Jie Deng, Hong Chen, Peng Liu, Lihua Zheng, et al.. A CEP Peptide ReceptorLike Kinase Regulates Auxin Biosynthesis and Ethylene Signaling to Coordinate Root Growth and Symbiotic Nodulation in Medicago truncatula. The Plant cell, 2020, 32 (9), pp.2855-2877. 10.1105/tpc.20.00248 . hal-03063926

\author{
HAL Id: hal-03063926 \\ https://hal.science/hal-03063926
}

Submitted on 17 Dec 2020

HAL is a multi-disciplinary open access archive for the deposit and dissemination of scientific research documents, whether they are published or not. The documents may come from teaching and research institutions in France or abroad, or from public or private research centers.
L'archive ouverte pluridisciplinaire HAL, est destinée au dépôt et à la diffusion de documents scientifiques de niveau recherche, publiés ou non, émanant des établissements d'enseignement et de recherche français ou étrangers, des laboratoires publics ou privés. 


\title{
A CEP Peptide Receptor-Like Kinase Regulates Auxin Biosynthesis and Ethylene Signaling to Coordinate Root Growth and Symbiotic Nodulation in Medicago truncatula ${ }^{[\mathrm{OPEN}]}$
}

\author{
Fugui Zhu, a,b Jie Deng, ${ }^{a}$ Hong Chen, a,b Peng Liu, ${ }^{a}$ Lihua Zheng, ${ }^{a}$ Qinyi Ye, ${ }^{a}$ Rui Li, ${ }^{a}$ Mathias Brault,c Jiangqi Wen, ${ }^{d}$ \\ Florian Frugier, ${ }^{c}$ Jiangli Dong, ${ }^{a, 1}$ and Tao Wang ${ }^{a, 1}$ \\ a State Key Laboratory of Agrobiotechnology, College of Biological Sciences, China Agricultural University, Beijing 100193, China \\ b College of Grassland Sciences, China Agricultural University, Beijing 100193, China \\ c Institute of Plant Sciences Paris-Saclay, Centre National de la Recherche Scientifique, Institut National de la Recherche \\ Agronomique, Université d'Evry, Université de Paris, Université Paris-Saclay, Gif-sur-Yvette 91190, France \\ dPlant Biology Division, Samuel Roberts Noble Research Institute, Ardmore, Oklahoma 73401
}

ORCID IDs: 0000-0002-2399-3258 (F.Z.); 0000-0002-4040-1402 (J.D.); 0000-0001-8673-6059 (H.C.); 0000-0001-5902-841X (P.L.); 0000-0003-2443-8552 (L.Z.); 0000-0002-7464-2095 (Q.Y.); 0000-0002-5986-2663 (R.L.); 0000-0001-8296-6551 (M.B.); 0000-00015113-7750 (J.W.); 0000-0002-9783-7418 (F.F.); 0000-0003-2643-6358 (J.D.); 0000-0002-4001-9828 (T.W.)

\begin{abstract}
Because of the large amount of energy consumed during symbiotic nitrogen fixation, legumes must balance growth and symbiotic nodulation. Both lateral roots and nodules form on the root system, and the developmental coordination of these organs under conditions of reduced nitrogen $(\mathrm{N})$ availability remains elusive. We show that the Medicago truncatula COMPACT ROOT ARCHITECTURE2 (MTCRA2) receptor-like kinase is essential to promote the initiation of early symbiotic nodulation and to inhibit root growth in response to low N. C-TERMINALLY ENCODED PEPTIDE (MTCEP1) peptides can activate MtCRA2 under N-starvation conditions, leading to a repression of YUCCA2 (MtYUC2) auxin biosynthesis gene expression, and therefore of auxin root responses. Accordingly, the compact root architecture phenotype of cra2 can be mimicked by an auxin treatment or by overexpressing MtYUC2, and conversely, a treatment with YUC inhibitors or an MtYUC2 knockout rescues the cra2 root phenotype. The MtCEP1-activated CRA2 can additionally interact with and phosphorylate the MtEIN2 ethylene signaling component at Ser ${ }^{643}$ and Ser ${ }^{924}$, preventing its cleavage and thereby repressing ethylene responses, thus locally promoting the root susceptibility to rhizobia. In agreement with this interaction, the cra2 low nodulation phenotype is rescued by an ein2 mutation. Overall, by reducing auxin biosynthesis and inhibiting ethylene signaling, the MtCEP1/MtCRA2 pathway balances root and nodule development under low-N conditions.
\end{abstract}

\section{INTRODUCTION}

Plants possess an extremely plastic root system. The growth and architecture of roots are modulated according to extrinsic nitrogen (N) availability in the soil. In legumes, the root system architecture (RSA) involves the formation of $\mathrm{N}$-fixing root nodules as well as lateral roots. Under $\mathrm{N}$-limiting conditions, plants adapt their main and lateral root growth to facilitate $\mathrm{N}$-uptake efficiency (Xu et al., 2012). In particular, legumes form symbioses with rhizobia to initiate specialized root organs called nodules where atmospheric $\mathrm{N}_{2}$ is converted into ammonium $\left(\mathrm{NH}_{4}{ }^{+}\right)$to provide legumes with $\mathrm{N}$ and sustain their growth (Oldroyd et al., 2011). As lateral root and nodule development are energetically costly, the coordination of these two root-derived developmental processes to maintain an optimal number of organs relative to the carbon and $\mathrm{N}$ availability relies on regulatory mechanisms that remain largely unknown.

\footnotetext{
${ }^{1}$ Address correspondence to dongjl@cau.edu.cn and wangt@cau. edu.cn.

The author responsible for distribution of materials integral to the findings presented in this article in accordance with the policy described in the Instructions for Authors (www.plantcell.org) is: Tao Wang (wangt@cau. edu.cn).

${ }^{[O P E N]}$ Articles can be viewed without a subscription.

www.plantcell.org/cgi/doi/10.1105/tpc.19.00428
}

Both nodule and lateral root organogeneses are derived from divisions of root inner tissues adjacent to xylem poles, in a similar region close to the root apical meristem (Herrbach et al., 2014). Some developmental genes participate in the regulation of both nodule and lateral root meristems (Franssen et al., 2015; Schiessl et al., 2019; Soyano et al., 2019), in close coordination with signaling pathways involving phytohormones, microRNAs, and peptides acting either locally or systemically (Gonzalez-Rizzo et al., 2006; Desbrosses and Stougaard, 2011; Mohd-Radzman et al., 2013; Shabala et al., 2016; Gamas et al., 2017). Although several antagonistic and synergistic signaling pathways regulating lateral roots and nodules have been discovered, how lateral root and nodule development are coordinated by these signaling pathways remains elusive.

Recently, peptide-mediated signaling pathways, such as those involving CLAVATA3/ESR-RELATED (CLE) or C-TERMINALLY ENCODED PEPTIDE (CEP), were implicated in the positive and negative control of nodule and lateral root development and nitrate acquisition in relation to nitrate $\left(\mathrm{NO}_{3}{ }^{-}\right)$availability (Imin et al., 2013; Araya et al., 2014; Ohkubo et al., 2017). To balance the extra energy costs required for symbiotic $\mathrm{N}$ fixation, the expression of specific CLE peptides encoding genes is up-regulated in response to high $\mathrm{N}$ or by existing nodules to optimize the total nodule number regarding the whole-plant $\mathrm{N}$ needs (Djordjevic et al., 
2015). This autoregulation of nodulation (AON) pathway in Lotus japonicus involves cytokinins and the miR2111 microRNA downstream of the HYPERNODULATION AND ABERRANT ROOT FORMATION1 (HAR1) leucine-rich repeat receptor-like kinase (LRR-RLK) to limit the number of symbiotic nodules formed (Sasaki et al., 2014; Tsikou et al., 2018). In Medicago truncatula, signaling peptides from the CEP family, such as MtCEP1, exhibit a positive effect on nodulation and a negative effect on lateral root emergence under low $N$ availability (Imin et al., 2013). The MtCEP1 precursor contains two CEP peptide domains with different posttranslational hydroxylation patterns that have an antagonistic ability to regulate lateral roots and nodules (MohdRadzman et al., 2015; Patel et al., 2018). A recent study additionally pointed out that MtCEP1 peptides increase the number of nodules, depending on the early symbiotic signaling pathway and on the ETHYLENE INSENSITIVE2 (MtEIN2)/SICKLE (SKL) ethylene signaling pathway but not on the SUNN-mediated AON pathway (that is functionally homologous to LjHAR1; MohdRadzman et al., 2016). The ethylene pathway is, however, only negatively regulated by MtCEP1 peptides in relation to early nodulation but not in relation to the MtCEP1-mediated inhibition of lateral root formation.

The plant gaseous hormone ethylene indeed negatively affects rhizobium infections and nodule formation, and the Mtein2/skl mutant or Ljein2a/Ljein2b mutants exhibit rhizobium hyperinfection and hypernodulation phenotypes (Penmetsa et al., 2003; Reid et al., 2018). The ethylene/EIN2 pathway disrupts the symbiotic pathway at a very early stage, inhibiting both the initiation and frequency of rhizobium-induced calcium spiking (Oldroyd et al., 2001). Comprehensive transcriptional profiling (Larrainzar et al., 2015) inferred that ethylene biosynthesis and response are rapidly activated by rhizobia within $M$. truncatula roots, which is consistent with an accumulation of ethylene negatively regulating infection (Oldroyd et al., 2001; Penmetsa et al., 2008). This result implies that to maintain root susceptibility to rhizobia, a mechanism may be needed to actively repress the inhibition of nodulation by ethylene.

Recently, another LRR-RLK, referred to as CRA2 (COMPACT ROOT ARCHITECTURE2), was identified in M. truncatula (Huault et al., 2014; Laffont et al., 2019). The cra2 mutant forms a reduced number of symbiotic nodules and an increased number of lateral roots. Grafting experiments indicated that nodule initiation is controlled by MtCRA2 systemically from shoots and lateral root formation locally within roots (Huault et al., 2014). The MtCRA2 receptor-like kinase is most closely related to XYLEM INTERMIXED WITH PHLOEM1/CEP RECEPTOR1 (XIP1/CEPR1) in Arabidopsis (Arabidopsis thaliana), which was shown to bind AtCEP1 peptides and systemically regulate nitrate uptake through the systemic effectors CEP DOWNSTREAM1/2 (CEPD1/2) and CEPD-LIKE2 (Huault et al., 2014; Tabata et al., 2014; Ohkubo et al., 2017; Ota et al., 2020). As root and nodule number phenotypes of MtCEP1-expressing roots and of cra2 mutants are opposite (Imin et al., 2013; Huault et al., 2014), this strongly suggests that CEP peptides could act depending on the MtCRA2 receptor, as recently demonstrated by Mohd-Radzman et al. (2016). Although, currently, there is no direct evidence that CEP peptides physically bind to the MtCRA2 receptor, this result nevertheless suggests that MtCRA2 is a likely receptor for MtCEP1 peptides in $M$. truncatula. Taken together, these results suggest that the MtCRA2 pathway is in a central position to balance lateral root and nodule development under low- $\mathrm{N}$ conditions, even though downstream molecular pathways regulated by MtCRA2 remain poorly understood.

The auxin phytohormone is essential for various organogeneses in plants, and especially lateral root formation (Liu et al., 2018). Auxin also regulates nodulation, as exogenous application of a high concentration $(50 \mathrm{mM})$ of the synthetic auxin 2,4-D or of 1$\mathrm{N}$-naphthylphthalamic acid (NPA) or 2,3,5-triiodobenzoic acid (TIBA) auxin transport inhibitors induced "pseudo-nodule" formation on legume or rice (Oryza sativa) roots (Hiltenbrand et al., 2016). Recently, Wang et al. (2019) reported that the overexpression of the indole-3-pyruvate monooxygenase YUCCA2 (GmYUC2a) gene, which is required for the last step of indole-3acetic acid (IAA) auxin biosynthesis, altered root hair deformation and reduced nodule number. In addition, mutation of $\angle O B-D O-$ MAIN PROTEIN16 (LBD16), regulating YUC gene expression, led to defective nodule and lateral root initiation, whereas, conversely, $\angle B D 16$ or YUC2 overexpression promoted lateral root formation (Schiessl et al., 2019). In addition, the LIKE AUXIN RESISTANT2 (MtLAX2) auxin transporter inhibits nodulation by locally regulating auxin accumulation in the root cortex (Roy et al., 2017), and the RNA interference of PIN-FORMED2 (MtPIN2), MtPIN3, and MtPIN4 can reduce the nodule number (Huo et al., 2006). Overall, these results indicate that both YUC-dependent auxin biosynthesis and PIN-mediated, LAX-dependent auxin transport are involved in the regulation of nodule initiation.

In this study, we show that MtCRA2 regulates RSA and nodulation, respectively, through the auxin and ethylene pathways. On the one hand, MtCEP1 activation of the MtCRA2 receptor represses transcriptionally auxin biosynthesis, and notably, the expression of the MtYUC2 gene, which is associated with reduced auxin content in roots, increased main root growth and decreased lateral root formation. On the other hand, the MtCEP1-activated MtCRA2 receptor autophosphorylates and transphosphorylates MtEIN2 on Ser643 and Ser ${ }^{924}$, which inhibits MtEIN2 cleavage depending on $\mathrm{N}$ availability and thus interrupts the ethylene signaling pathway that inhibits rhizobial infections under low $\mathrm{N}$, making the plant roots more actively susceptible to rhizobium. These results reveal a dual mechanism wherein the MtCRA2 signaling pathway balances lateral root and nodule development by reducing auxin biosynthesis and inhibiting the ethylene response under low- $\mathrm{N}$ conditions, respectively.

\section{RESULTS}

\section{MtCRA2 Antagonistically Regulates Root Architecture and Symbiotic Nodulation}

Using forward genetic screens, we identified from the $M$. truncatula R108 Tnt1 insertional mutant collection two mutants (NF0903 and NF0805) that display an increased lateral root number and a decreased nodule number (Figure 1A). These phenotypes corresponded to the previously described "compact root architecture" mutant phenotypes (Laffont et al., 2010; Huault et al., 2014), and accordingly, Tnt1 flanking sequence tags 

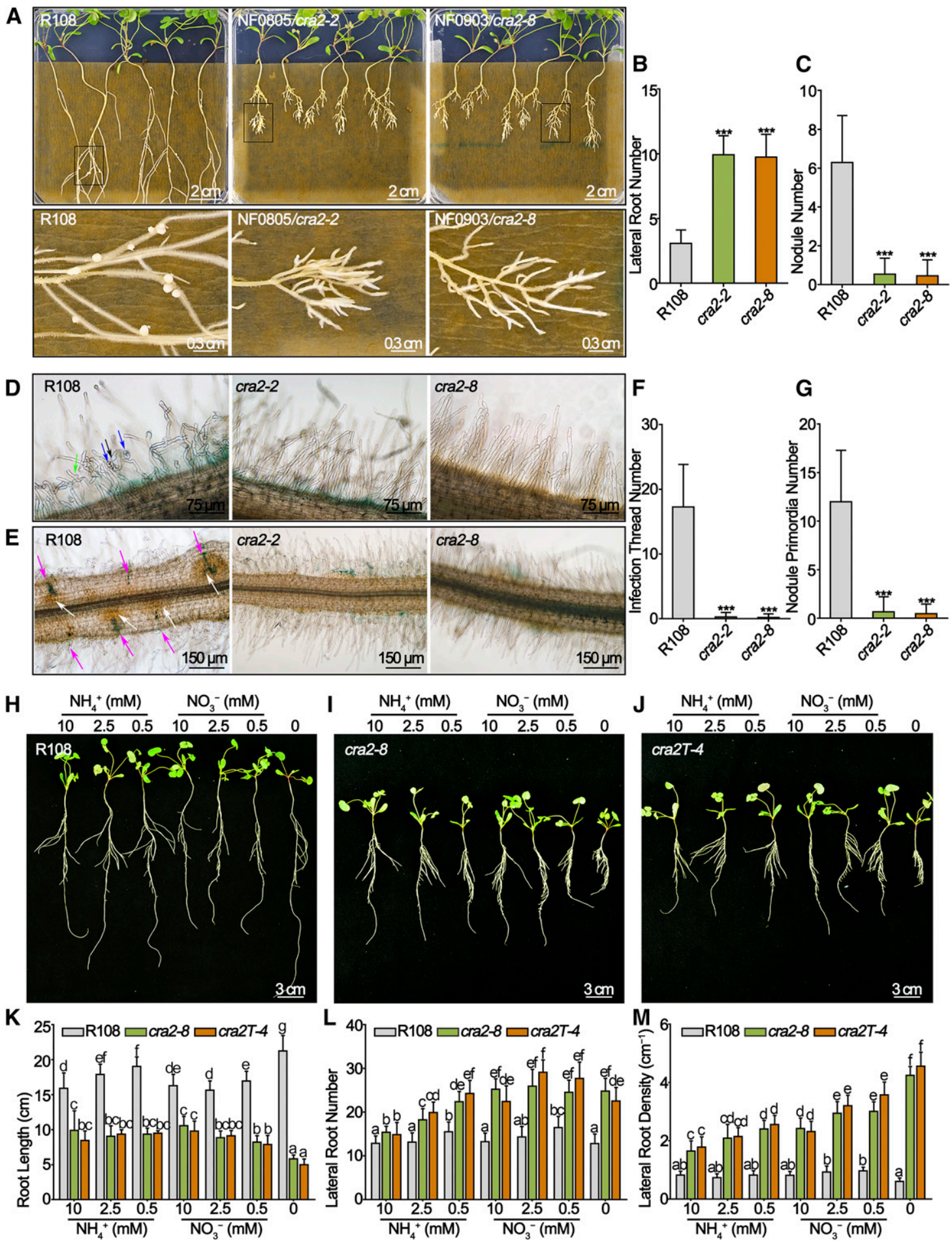

Figure 1. MtCRA2 Regulates the Root Architecture and Symbiotic Nodulation.

(A) Representative examples of the lateral root and nodule development of R108, cra2-2, and cra2-8 plants at 21 DAl. Enlargements of the boxed regions are shown in the lower panels. Germinated seedlings were grown on plates with solidified N-deprived medium for $7 \mathrm{~d}$ and then inoculated with Sm1021. (B) and (C) Quantification of the lateral root number (B) and nodule number (C) at 14 DAl. Similar results were obtained in three independent experiments. The data are means \pm SD from one representative experiment, and an ANOVA with a posthoc Tukey's test was used $\left(^{\star \star \star}, \mathrm{P}<0.001, n=24\right.$; Supplemental Data Set 3).

(D) to (G) Early rhizobial infection events in 7-d-old R108, cra2-2, and cra2-8 plants inoculated with an Sm1021 strain carrying the ProHemA:LACZ fusion. 
available in the $M$. truncatula Mutant Database at the Noble Foundation revealed a Tnt1 insertion in the MtCRA2 locus (Medtr3g110840) in the NF0903 mutant line, which was located between $\mathrm{G}^{1785}$ and $\mathrm{G}^{1786}$ in the open reading frame, causing the knockout of MtCRA2 (Supplemental Figure 1A). However, no Tnt1 flanking sequence tag was associated with this locus in the NF0805 mutant line, but sequencing of the MtCRA2 open reading frame revealed that the missing $A^{922}$ caused premature termination at $\operatorname{Ser}^{323}$ (Supplemental Figure $1 \mathrm{~A}$ ). These results are in agreement with Huault et al. (2014), and we therefore accordingly named these cra2 mutant alleles cra2-2/NF0805 and cra2-8/ NF0903.

Detailed quantification of nodule and lateral root numbers revealed that, compared with $\mathrm{R} 108$, cra2 presented significantly fewer nodules but more lateral roots (Figures $1 \mathrm{~B}$ and $1 \mathrm{C}$ ). Early rhizobial infection events were assayed in R108 and cra2 with a Sinorhizobium meliloti 1021 (Sm1021) strain carrying a ProHe$m A: L A C Z$ reporter. Curled root hairs, infected pockets, root hair tip swelling, and root hair branching were detected $36 \mathrm{~h}$ postinoculation in R108 but not in cra2 (Figure 1D). The quantification of infection threads and nodule primordia at $5 \mathrm{~d}$ after inoculation (DAl) revealed that infection thread and nodule primordia formation were nearly abolished in the cra2 mutant compared with R108 (Figures 1E to $1 \mathrm{G}$ ). These results suggest that MtCRA2 may regulate the rhizobial infection process.

Because the genetic background of these mutants contains many undesirable Tnt1 insertions, we independently generated cra2 mutants using the transcription activator-like effector nuclease (TALEN) technology. Representative mutants with homozygous or biallelic mutations causing a translational frameshift were selected (Supplemental Figure 1B), and cra2-8 and cra2T-4 alleles were retained for subsequent experiments.

As the level of $\mathrm{N}$ influences RSA, the cra2 and R108 root phenotypes were analyzed under various $\mathrm{NO}_{3}{ }^{-}$and $\mathrm{NH}_{4}{ }^{+}$concentrations. When $\mathrm{NO}_{3}{ }^{-}$or $\mathrm{NH}_{4}{ }^{+}$concentrations were decreased, R108 presented a longer primary root and fewer lateral roots (Figures $1 \mathrm{H}$ to $1 \mathrm{M}$ ), whereas cra2-8 and cra2 $T-4$ mutants, in contrast, showed shorter primary roots and increased lateral root densities (Figures $1 \mathrm{~K}$ to $1 \mathrm{M}$ ). The primary and lateral root phenotypes of cra2 were relatively stronger compared with R108 under low- $\mathrm{N}$ conditions than under high- $\mathrm{N}$ conditions. In addition, the lateral root phenotype of cra2 is stronger when grown on $\mathrm{NO}_{3}$ than on $\mathrm{NH}_{4}{ }^{+}$(Figures $1 \mathrm{H}$ to $1 \mathrm{M}$ ). These results indicate that cra2 mutants can perceive changes in $\mathrm{N}$ availability but show a notably altered root developmental response under $\mathrm{N}$ starvation.

\section{Transcriptome Analysis of Shoots and Rhizobium-Infected Roots of the cra2 Mutant}

To identify downstream molecular targets in shoots and roots that depend on the MtCRA2 receptor to regulate lateral root and symbiotic nodulation, an RNA sequencing (RNA-seq) analysis was performed on $\mathrm{R} 108$ and cra2T-4 plants grown in a low-N medium for $7 \mathrm{~d}$ and then inoculated with $\mathrm{Sm} 1021$ for $5 \mathrm{~d}$. The RNAseq data revealed 2935 differentially expressed genes (DEGs) between cra2 and R108 roots, among which 1840 genes were downregulated and 1095 genes were upregulated. Only 381 DEGs were identified, however, in shoots (Supplemental Figures $2 \mathrm{~A}$ and $2 \mathrm{~B})$, suggesting that the main action of the MtCRA2 pathway lies in the root system.

A Kyoto Encyclopedia of Genes and Genomes pathway analysis revealed that upregulated genes were enriched for plant hormone signaling, plant-pathogen interactions, glutathione metabolism, and ABC transporters (Supplemental Figure 2C). Downregulated genes were enriched for amino acid and nucleotide biosynthesis, which can directly or indirectly influence plant growth by affecting plant hormone metabolism, and the biosynthesis of various secondary metabolites such as phenylpropanoids, lignin, and Phe, which are associated with plant cell walls, as well as flavonoids, which are well-known nodulation effectors (Supplemental Figure 2D).

When focusing on genes related to symbiotic nodulation and $\mathrm{N}$ responses, we observed that the expression of typical symbiosisrelated genes, such as those encoding NF receptors, NF signaling factors, transcriptional regulators, and downstream symbiosis marker genes, was significantly reduced in cra2 roots (Supplemental Figures $3 \mathrm{~A}$ and $3 \mathrm{~B}$ ), coinciding with the decreased nodule and infection thread number phenotype of cra2. In addition, several $\mathrm{NO}_{3}{ }^{-}$transporter- and $\mathrm{NO}_{3}{ }^{-}$reductase-encoding genes were differentially expressed between cra2 and R108. Among the $97 \mathrm{NO}_{3}{ }^{-}$TRANSPORTER1/PEPTIDE TRANSPORTER (NRT/NPFs) genes identified in M. truncatula (Pellizzaro et al., 2017), 18 NPF genes were downregulated in cra2 (Supplemental Figures $3 \mathrm{C}$ and $3 \mathrm{D}$ ), and the NRT2 family gene MtNRT2. 1 was also downregulated. These results suggest that MtCRA2 may be required to upregulate the expression of putative $\mathrm{NO}_{3}{ }^{-}$transporters and therefore to promote $\mathrm{N}$ acquisition.

The RNA-seq data also showed that many genes related to auxin metabolism and transport were differentially expressed between cra2 and R108 roots (Figures $2 \mathrm{~A}$ and $2 \mathrm{~B}$ ). Among these genes, the expression of $M T Y U C 2$, which is a rate-limiting enzyme in IAA biosynthesis, was enriched in both cra2 roots and shoots

Figure 1. (continued).

(D) Root hair curling (blue arrow), swelling (black arrow), and branching (green arrow) at $36 \mathrm{~h}$ after inoculation.

(E) Infection threads (magenta arrows) and nodule primordia (white arrows) at 5 DAI.

(F) and (G) Quantification of infection threads (F) and nodule primordia (G). Similar results were obtained in three independent experiments. The data are means \pm SD from one representative experiment, and an ANOVA with a posthoc Tukey's test was used ( ${ }^{\star \star \star}, \mathrm{P}<0.001, n=15$; Supplemental Data Set 3 ). (H) to (M) N relationship with the root phenotypes of R108, cra2-8, and cra2T-4. Germinated seedlings were grown in liquid Fåhraeus medium supplemented with $0,0.5,2.5$, or $10 \mathrm{mMNO}_{3}{ }^{-}$or $\mathrm{NH}_{4}{ }^{+}$for $12 \mathrm{~d}$. Representative images of $\mathrm{R} 108(\mathbf{H}), \operatorname{cra2}-8(\mathbf{I})$, and cra2 $\mathrm{T}-4(\mathbf{J})$ and the quantification of the primary root length (K), lateral root number (L), and lateral root density (M) are shown. Similar results were obtained in three independent experiments. The data are means \pm SD from one representative experiment, and significant differences were determined with a Kruskal-Wallis statistical test, indicated by letters $(P<0.05, n=15$; Supplemental Data Set 3). 
A

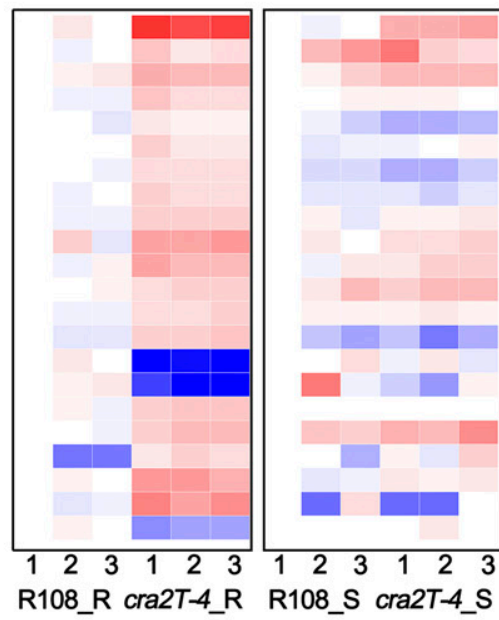
R108_R cra2T-4_R R108_S cra2T-4_S

D

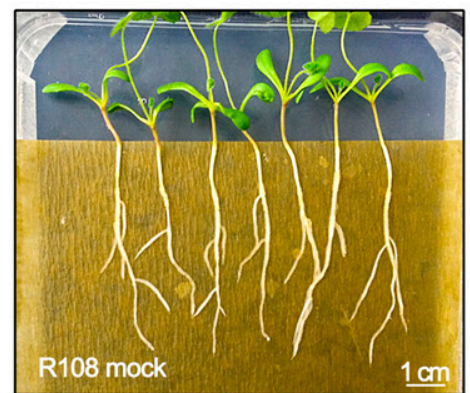

E

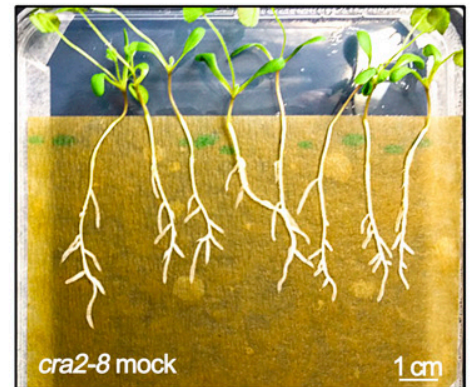

F

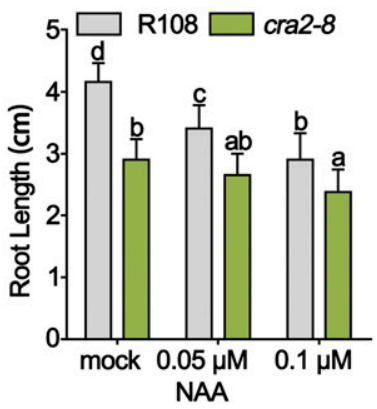

Medtr6g086870 MtYUC2

Medtr4g127100 PIN2

Medir4g127100 PIN2

Medtr6g069510 PIN4

Medtr7g089360 PIN10 C

Medtrog100050

Medtr8g027440

Medtr4g021580

Medtr1g064430

Medtr6g488150

Medtr1g070520

Medtr7g096090

Medtr7g096090

Medtr8g103030

Medtr1g085750

Medtr3g113310

Medurgo63330

Medrrig009150 ک

Medtrosos 0020

Medtrig063950

Medtr5g083960

Medtr3g031660
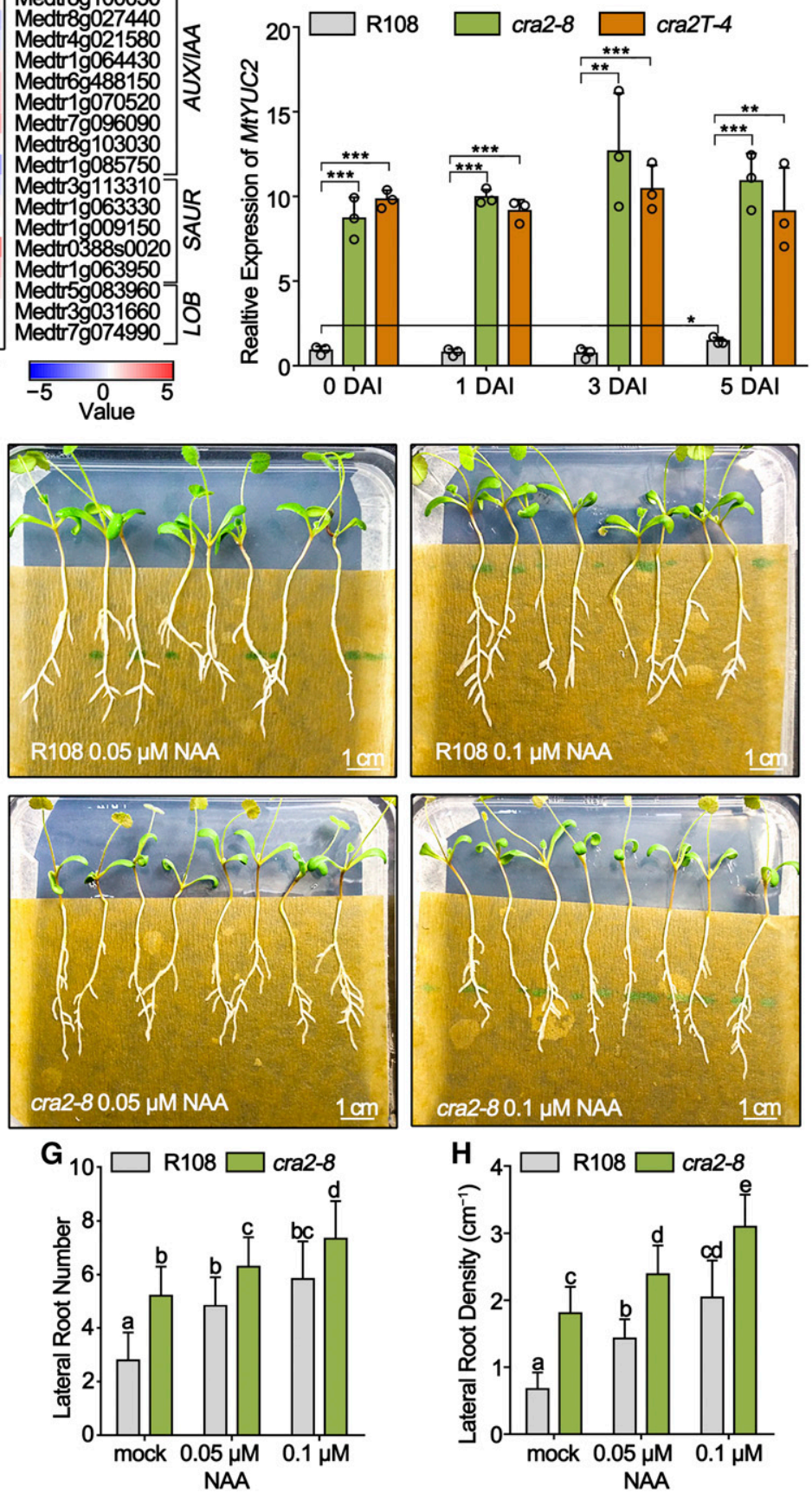

Figure 2. Transcriptome Analysis of the cra2 Mutant.

(A) and (B) RNA-seq expression heatmaps of selected genes involved in auxin biosynthesis and the auxin response. The heatmaps represent relative log ${ }_{2}$ -transformed expression values (average counts of fragments per kilobase of transcript per million mapped reads). Root (R) and shoot (S) samples are normalized with the R108_R1 sample and the R108_S1 sample, respectively. R1 to R3 indicate three independent biological replicates. AUX/IAA, auxin/indoleacetic acid response genes; $L O B$, lateral organ boundaries; SAUR, small auxin-up RNA. 
compared with R108 (Figures 2A and 2B). A systematic analysis of the 16 YUC genes identified in the $M$. truncatula genome revealed that only the expression of MtYUC2 was significantly increased in the shoots and roots of cra2 compared with R108 (Supplemental Figure 4). RT-qPCR showed that, relative to R108, MtYUC2 expression was upregulated in cra2 roots at $0,1,3$, and 5 DAl (Figure 2C). RNA-seq data also showed that a subset of early auxin-responsive genes from the auxin/IAA and small auxin-up RNA families, as well as PIN-encoding genes, were upregulated in cra2 (Figures 2A and 2B). RT-qPCR analysis of all 10PIN and $5 L A X$ genes showed that MtPIN2 and MtPIN7 were upregulated in cra2 (Supplemental Figure 5A). The quantification of acropetal polar auxin transport in roots revealed that polar auxin transport is greater in cra2 than in R108 (Supplemental Figure 5B). Based on these data, we hypothesized that the increased lateral root number and the decreased nodule number in the cra2 mutant may be caused by defects in auxin metabolism and/or transport activity in roots.

\section{The Low Nodulation Phenotype of cra2 Is Not Due to the Accumulation of Auxin or Defects in Auxin Transport}

To determine the relationship between auxin and the low nodulation phenotype of cra2, we treated R108 and cra2 mutants with the 1-naphthylacetic acid (NAA) auxin or with two different YUC inhibitors, 4-biphenyl boronic acid (BBo) or 4-phenoxyphenyl boronic acid (PPBo; Kakei et al., 2015), and the nodule number was quantified. The NAA treatment did not reduce the nodule number of R108 or cra2 (Supplemental Figure 6), although nodules remained underdeveloped and white, which was suggestive of their altered development and metabolic activity. Furthermore, treatment with the BBo and PPBo YUC inhibitors had no significant effect on the nodule number of R108 or cra2 (Supplemental Figure 7). These results suggest that the low nodulation phenotype of the cra2 mutant is not tightly linked to an auxin content defect.

The polar auxin transport inhibitors NPA and TIBA can trigger the formation of pseudonodules and rescue the nodulation defects of the cre 1 cytokinin receptor mutant that correspond with unrestricted polar auxin transport ( $\mathrm{Ng}$ et al., 2015). TIBA flooding treatments were used to induce pseudonodules, of which the number did not significantly differ between cra2 and R108 (Supplemental Figure 8); however, when inoculated with rhizobia, TIBA-treated R108 roots formed more nodules, whereas cra2 mutants showed no significant change in their nodule number (Supplemental Figure 8). These results reveal that pseudonodules triggered by TIBA can form independently of MtCRA2 and that TIBA cannot rescue the cra2 low nodulation phenotype.

\section{NAA Treatment Mimics the Compact Root Architecture Phenotype of cra2 and the Inhibition of YUC Activity Partially Rescues cra2 Root Phenotypes}

To elucidate the relationships between the cra2 root phenotypes, auxin biosynthesis, and auxin transport, we first treated R108 and cra2 plants with 0.05 or $0.1 \mu \mathrm{M} N A A$ and assessed the primary root growth and lateral root formation. These NAA treatments promoted lateral root formation and restricted the primary root growth of R108 and cra2 in a concentration-dependent manner (Figures $2 \mathrm{D}$ to $2 \mathrm{H}$ ). Moreover, the lateral root and primary root lengths did not significantly differ between R108 treated with $0.1 \mu \mathrm{MNAA}$ and cra2 treated with $0.05 \mu \mathrm{M}$ or without NAA (Figures $2 \mathrm{D}$ to $2 \mathrm{H}$ ). These results indicated that NAA treatment of R108 mimicked the compact root architecture phenotype of cra2. Second, we used the NPA polar auxin transport inhibitor, which suppressed the lateral root and primary root growth in cra2 and R108, whereas the lateral root density of cra2 treated with NPA remained significantly higher compared with R108 (Supplemental Figures 5C to 5F). This result suggests that the increased acropetal polar auxin transport previously detected in cra2 may not be the major cause of the compact root architecture phenotype.

To determine whether the cra2 compact root architecture phenotype could be alternatively caused by the constitutive overexpression of MtYUC2, we used the BBo YUC inhibitor, which inhibited lateral root formation and promoted primary root growth in both R108 and cra2 (Figures 3A to 3D). Moreover, the number and density of the cra2 lateral roots were partially restored by the YUC inhibitor treatment to the level of nontreated R108 controls (Figures 3B to 3D). To circumvent the pleiotropic effect of the YUC inhibitor on all members of the YUC family, genetic experiments were independently performed.

As a gain-of-function approach, MtYUC2 was first overexpressed in $\mathrm{R} 108$ roots by transforming with the Pro35S:MTYUC2FLAG construct, and transgenic roots were selected based on $\beta$-glucuronidase (GUS) staining used as a transformation marker (Figure 3E). Roots overexpressing MtYUC2 formed an increased number of shorter lateral roots compared with roots transformed with a Pro35S:FLAG empty vector control (Figures $3 \mathrm{~F}$ to $3 \mathrm{H}$ ). This root phenotype was associated with an increased MtYUC2 transcript level (Figures 3F to 3I). Second, the MtYUC2 gene was deleted using clustered regularly interspaced short palindromic

Figure 2. (continued).

(C) RT-qPCR analysis of the expression of MtYUC2 in R108, cra2-8, and cra2T-4 roots at 0, 1, 3, and 5 DAl. Germinated seedlings were grown in solidified $\mathrm{N}$-deprived medium for $7 \mathrm{~d}$ and then inoculated with $\mathrm{Sm} 1021$. All samples are normalized with R108 at $0 \mathrm{DAl}$. Data were derived from three independent pools of roots. The data are means $\pm \mathrm{SD}$, and a paired two-tailed Student's $t$ test was used ( ${ }^{*}, \mathrm{P}<0.05 ;{ }^{\star *}, \mathrm{P}<0.01$; and ${ }^{* \star *}$, $\mathrm{P}<0.001$; Supplemental Data Set 3 ). (D) to (H) Effect of the NAA auxin on the root development of R108 and cra2-8. Germinated seedlings were grown in plates containing solidified half-strength Murashige and Skoog medium (without Suc) and 0, 0.05, or $0.1 \mu \mathrm{M}$ NAA for $10 \mathrm{~d}$.

(D) and (E) Representative images of R108 (D) and cra2-8 (E).

$(\mathbf{F})$ to $(\mathbf{H})$ Quantification of primary root length $(\mathbf{F})$, lateral root number $(\mathbf{G})$, and lateral root density $(\mathbf{H})$. Similar results were obtained in three independent experiments. The data are means \pm SD from one representative experiment, and significant differences were determined with an ANOVA with a posthoc Tukey's test, indicated by letters $(P<0.05, n=24$; Supplemental Data Set 3$)$. 

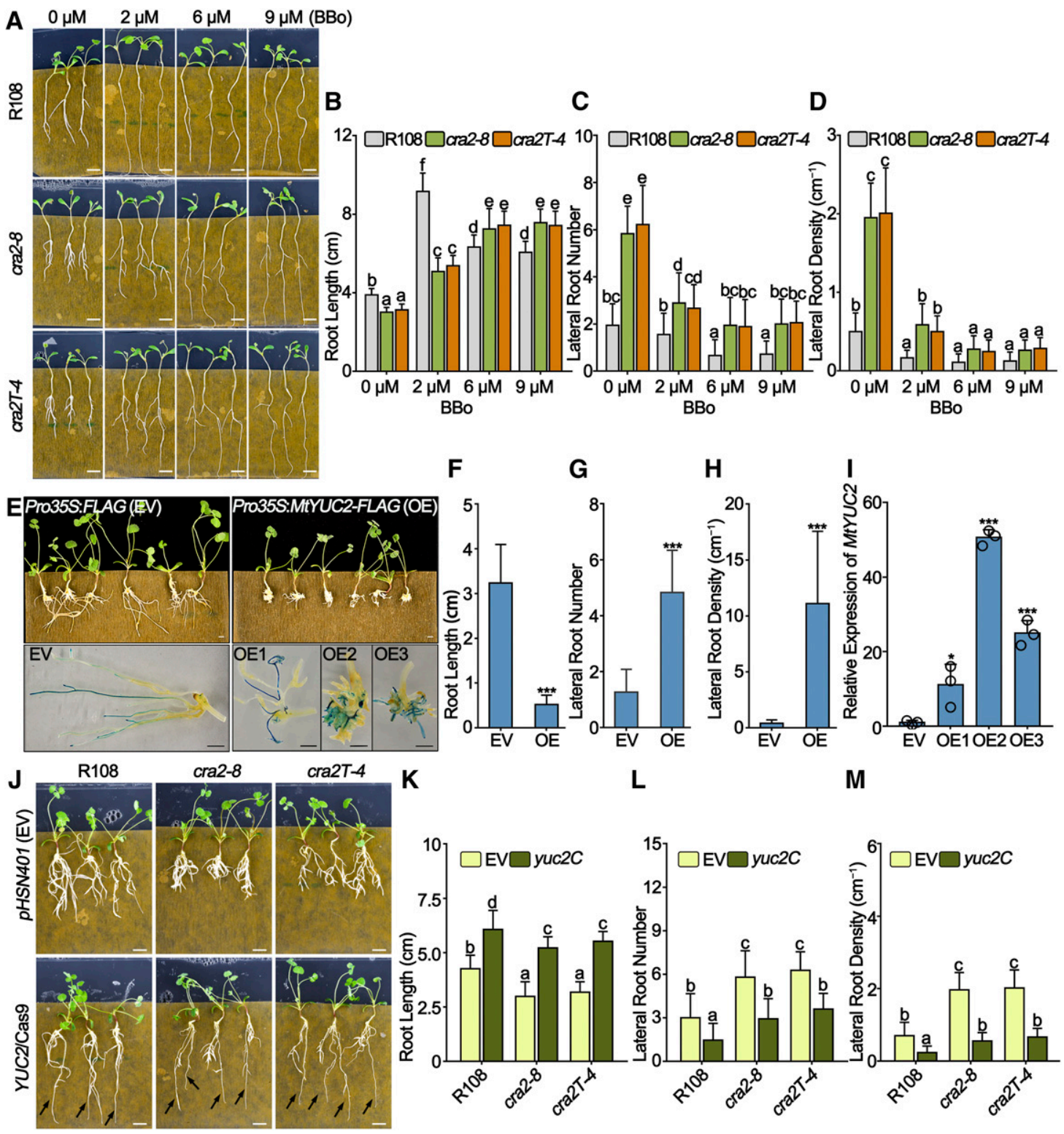
K
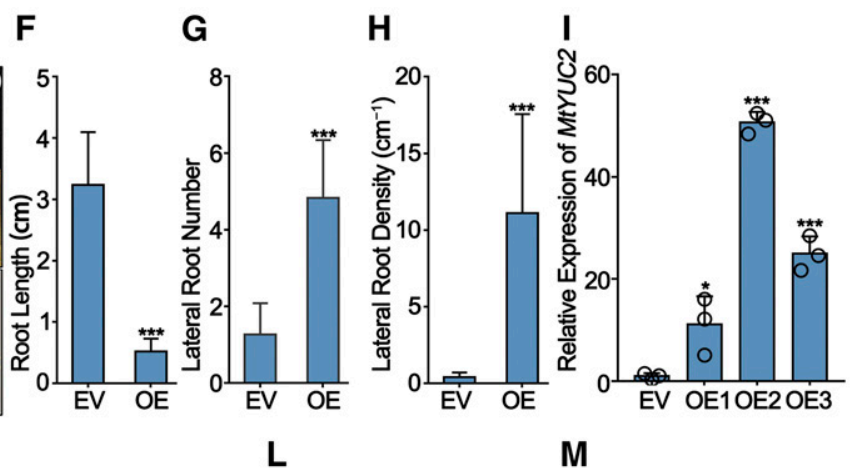

$\mathbf{L}$

M
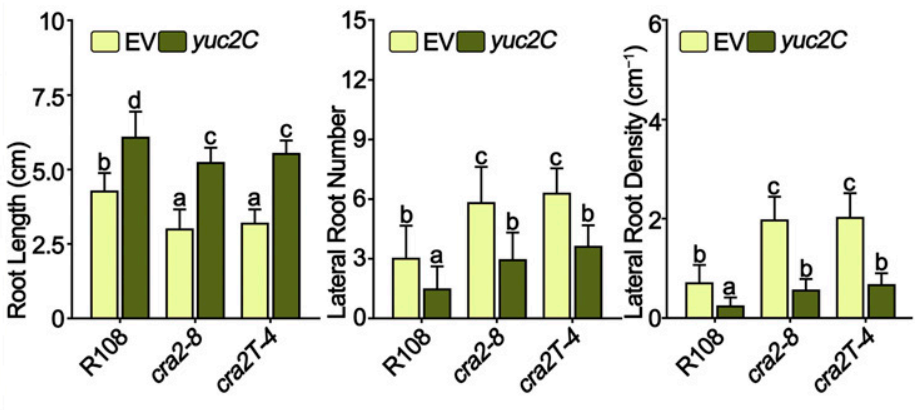

Figure 3. MtYUC2 Regulates the Root Architecture Depending on MtCRA2.

(A) to (D) Effects of a YUC inhibitor (BBo) on the root development of R108, cra2-8, and cra2T-4. Germinated seedlings were grown on plates containing solidified half-strength Murashige and Skoog medium (without Suc) with 2, 6, or $9 \mu \mathrm{M}$ BBo for $10 \mathrm{~d}$. Representative images of root growth (A) and the quantification of the root length (B), lateral root number (C), and lateral root density (D) are shown. Similar results were obtained in three independent experiments. The data are means \pm SD from one representative experiment, and significant differences were determined with an ANOVA with a posthoc Duncan's test, as indicated by letters $(\mathrm{P}<0.05, n=18$; Supplemental Data Set 3$)$. Bars in $(\mathbf{A})=2 \mathrm{~cm}$.

(E) to (I) Effect of MtYUC2 overexpression on root development.

(E) Representative images of 3-week-old R108 roots transformed with the Pro35S:FLAG empty vector (EV; left panels) or the Pro35S:MtYUC2-FLAG overexpression vector (OE; right panels). The two vectors contained Pro35S:GUS as a transformation marker. The top images show composite plants before GUS staining, and the bottom images show GUS staining. Bars $=0.3 \mathrm{~cm}$.

$\mathbf{( F )}$ to $(\mathbf{H})$ Quantification of the root length $\mathbf{( F )}$, lateral root number $(\mathbf{G})$, and lateral root density $(\mathbf{H})$ of the transgenic roots of control and overexpression plants as described in (E). Similar results were obtained in two independent experiments. The data are means \pm SD from one representative experiment, and significant differences were determined with a Kruskal-Wallis test ${ }^{* \star \star}, \mathrm{P}<0.001, n=30$; Supplemental Data Set 3).

(I) Relative expression of the MtYUC2 transgene, as analyzed by RT-qPCR, showing that the expression level of MtYUC2 corresponds with the number of lateral roots observed in (E); OE1, OE2, and OE3 correspond to the representative roots OE1, OE2, and OE3 in (E). The data were derived from three different pools of roots. The data are means $\pm \mathrm{SD}$. All samples are normalized with the empty vector, and a paired two-tailed Student's $t$ test was used ${ }^{*}, \mathrm{P}<0.05$ and ${ }^{\star \star *}, \mathrm{P}<0.001$; Supplemental Data Set 3). 
repeats (CRISPR)/Cas9 strategy in both $\mathrm{R} 108$ and cra2 roots (Supplemental Figure 9). This MtYUC2 mutation (yuc2C) significantly increased the root length in R108 and decreased the lateral root number and density in cra2. Importantly, root length as well as the lateral root number and density of the cra2 mutant were partially rescued when combined with the yuc2C mutation (Figures 3J to 3M). Noteworthy, the effect of the Pro35S:MtYUC2FLAG construct on lateral root formation was more severe than that of the cra2 mutation, perhaps because the expression of MtYUC2 was higher in Pro35S:MtYUC2-FLAG roots than in cra2. These results collectively suggest that the compact root architecture phenotype of cra2 is tightly associated with the increased expression of MtYUC2 observed in the cra2 mutant.

\section{MtYUC2 Expression Is Repressed by the MtCRA2 Pathway and Reduces the Auxin Response under Low $\mathbf{N}$}

A comparative analysis of MtYUC2 transcript levels between cra2 and R108 in response to N starvation or to MtCEP1 treatment was performed using RT-qPCR. The expression of MtYUC2 was repressed in R108 but not in cra2 under low-N treatment for 8, 12, and $24 \mathrm{~h}$, which could induce the expression of MtCEP1 (Figure 4A; Supplemental Figure 10), and was also repressed by MtCEP1 treatment for 8, 12, and $24 \mathrm{~h}$ in R108 (Figure 4B). These results suggest that the MtCEP1/MtCRA2 pathway may mediate $\mathrm{N}$ limitation inputs to regulate MtYUC2 transcript levels.

Furthermore, a DR5:GUS reporter was used to evaluate the maximum auxin response in roots of cra2/DR5:GUS and R108/ DR5:GUS stable transgenic plants. The GUS staining intensity in $\mathrm{R} 108$ primary and lateral root tips was reduced under $\mathrm{N}$-starvation conditions, whereas it was unaffected in cra2 (Figure 4C). Finally, we used liquid chromatography-mass spectrometry (MS) to quantify endogenous IAA concentrations in roots of $\mathrm{R} 108$ and cra2 with or without $\mathrm{NO}_{3}-(10 \mathrm{mM})$. These quantitative data showed that the free IAA content was reduced under low-nitrate conditions in $\mathrm{R} 108$ roots compared with that under high-nitrate conditions, but this effect was not observed in cra2 roots. In addition, cra2 roots had a significantly higher IAA content compared with R108 roots under low-nitrate conditions (Figure 4D). These results collectively suggest that MtCEP1/MtCRA2 may control RSA by repressing MtYUC2 expression under low-N conditions, thereby reducing the auxin accumulation and response in root apical meristems.

\section{Mutation of MtEIN2 Partially Rescues the Symbiotic Nodulation of cra2}

The inhibitory function of the ethylene-MtEIN2/SKL pathway on rhizobia infections is well-documented, and it was recently proposed that the MtCEP1/MtCRA2 pathway may promote symbiotic nodulation by inhibiting ethylene signaling (Penmetsa and Cook, 1997; Mohd-Radzman et al., 2016). To further test this model, a CRISPR/Cas9 strategy based on two target sites was implemented to generate a stable ein2C mutant. We then generated a stable double mutant affecting MtEIN2 and MtCRA2 and selected several ein2C or cra2-8 ein2 $C$ mutant lines with homozygous or biallelic mutations causing a translational frameshift in MtEIN2 (Supplemental Figures 11A to 11D).

To determine the nodulation phenotypes of the ein2 $C$ and cra2 ein2 $C$ mutants, early infection events and nodule numbers were quantified in ein $2 \mathrm{C}-2$, ein $2 \mathrm{C}-3$, cra2 ein $2 \mathrm{C}-1$, and cra2 ein $2 \mathrm{C}-2$ mutants. Consistent with the hyperinfection phenotype of $s k l$ mutants reported in the Jemalong A17 genotype or in L. japonicus (Penmetsa and Cook, 1997; Reid et al., 2018), an increased number of infection threads and primordia were observed at $5 \mathrm{DAI}$ in ein $2 C$ compared with $\mathrm{R} 108$ and in cra2 ein $2 \mathrm{C}$ compared with cra2-8 (Figures $5 \mathrm{~A}$ to $5 \mathrm{C}$ ), even though fewer infection threads and primordia were observed in cra2 ein2 $C$ compared with ein2 $C$ (Figures 5B and 5C). Additionally, both ein $2 \mathrm{C}$ and cra2 ein2 $C$ exhibited increased nodule number phenotypes at 21 DAl compared with R108 and cra2-8, respectively (Figures 5D to 5l). Although the total number of nodules, primordia, and infection threads in cra2 ein $2 C$ reached the levels of those in $R 108$, these features remained lower than in ein2C. The nodule density (nodule number related to the root dry weight) of cra2 ein2 $C$, however, reached the level of ein $2 \mathrm{C}$ (Figures $5 \mathrm{H}$ and $5 \mathrm{I}$ ). Indeed, the root and shoot dry weights of ein $2 C$ were increased compared with $\mathrm{R} 108$, whereas no difference was detected between cra2 ein $2 \mathrm{C}$ and cra2-8 mutants (Figures 5F and 5G). cra2 ein $2 \mathrm{C}$ had longer roots and a lower lateral root density compared with cra2-8, which did not reach the levels observed in R108 (Supplemental Figures 11E to $11 \mathrm{H}$ ). To evaluate the potential relationship of the ein $2 \mathrm{C}$ induced ethylene signaling mutation with the YUC2 auxin pathway, which was previously shown to be altered in cra2, RT-qPCR was performed. The expression of MtYUC2 was not significantly different between $\mathrm{R} 108$ and ein2 roots under both high- and lownitrate conditions (Supplemental Figure 12). Overall, these results indicate that the cra2 ein $2 \mathrm{C}$ double mutant has partially rescued rhizobium susceptibility compared with the cra2 single mutant and that MtEIN2 likely participates in regulating root development independently of the transcriptional regulation of MtYUC2.

\section{MtCRA2 Is a Functional Kinase Activated by MtCEP1 Peptides That Can Phosphorylate MtEIN2/SKL}

To test the activity of the CRA2 receptor-like kinase, an in vitro phosphorylation assay with a GST-MtCRA2 ${ }^{\mathrm{KD}}$ (for CRA2 kinase

Figure 3. (continued).

(J) to (M) Effect of MtYUC2 deletion with CRISPR/Cas9 on the root growth of R108 and cra2.

(J) Representative images of 3-week-old R108, cra2-8, and cra2T-4 roots transformed with the CRISPR/Cas9 pHSN401 empty vector (top) or the pHSN401 vector harboring two target sites of MtYUC2 (MtYUC2/Cas9; bottom). The MtYUC2 knockout roots are indicated by arrows. Bars = $1 \mathrm{~cm}$.

(K) to (M) Quantification of the root length (K), lateral root number (L), and lateral root density (M) of R108, cra2, yuc2C, and cra2 yuc2C hairy roots as described in (J). Similar results were obtained in two independent experiments. The data are means \pm sD from one representative experiment, and significant differences were determined with an ANOVA with a posthoc Duncan's test, as indicated by letters $(P<0.05, n=15$; Supplemental Data Set 3). 

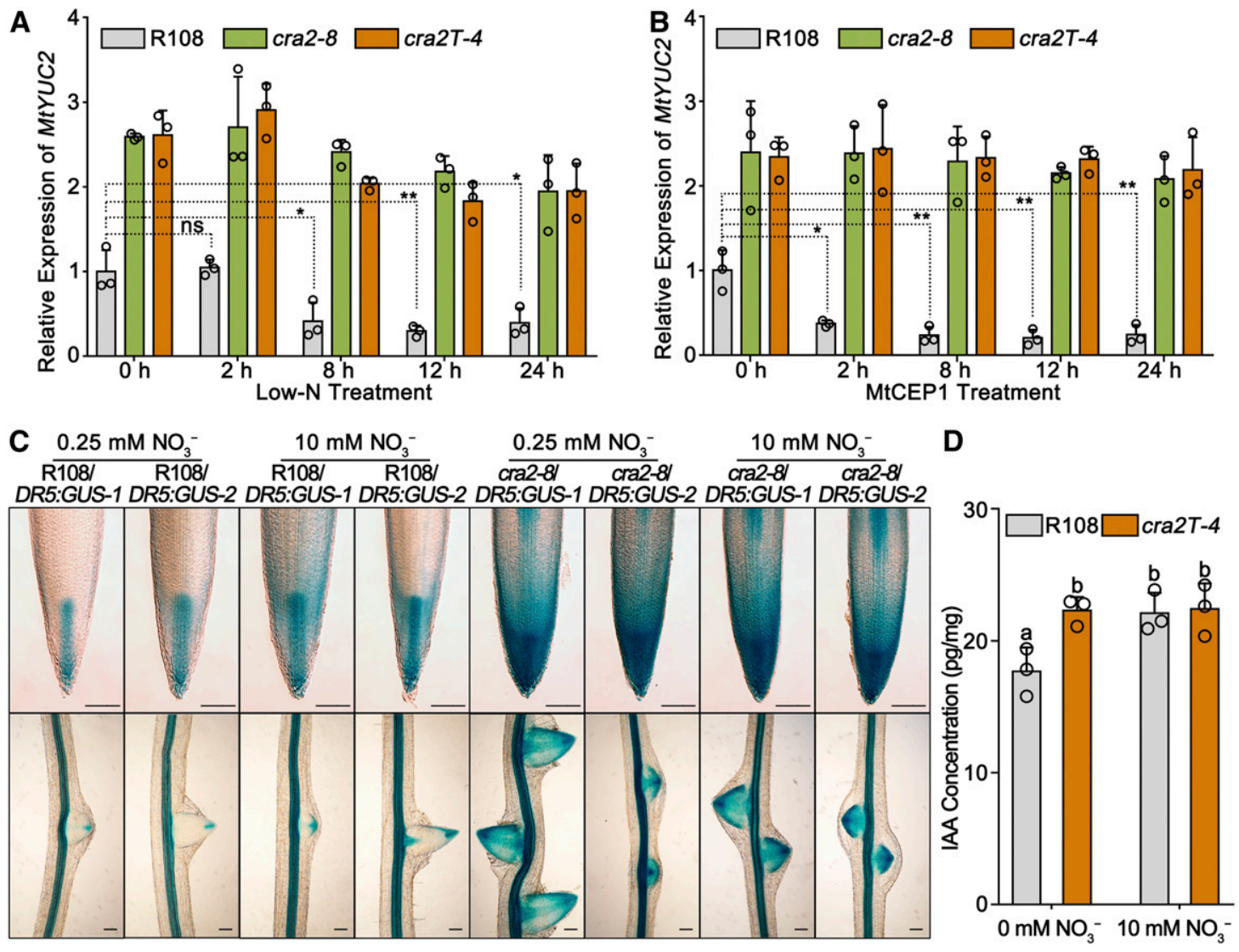

Figure 4. MtYUC2 Expression Is Repressed by the MtCEP1/MtCRA2 Pathway and Correlates with a Reduced Auxin Response in Roots under Low-N Conditions.

(A) and (B) RT-qPCR analysis of the expression of MtYUC2 in R108, cra2-8, and cra2T-4 grown without N and treated with MtCEP1 peptides.

(A) Germinated seedlings were grown in solidified Fåhraeus medium ( $10 \mathrm{mM} \mathrm{KNO}_{3}$ ) for $10 \mathrm{~d}$ and then transferred to Fåhraeus medium without $\mathrm{N}$ for $2,8,12$, and $24 \mathrm{~h}$.

(B) Germinated seedlings were grown in Fåhraeus medium (10 $\left.\mathrm{mM} \mathrm{KNO}_{3}\right)$ for $10 \mathrm{~d}$ and then transferred to the same medium containing $1 \mu \mathrm{M} \mathrm{MtCEP1}$ peptides for 2, 8, 12, and $24 \mathrm{~h}$.

The data were derived from three independent pools of roots. The data are means $\pm \mathrm{SD}$. All samples are normalized with R108 at $0 \mathrm{~h}$, and a paired two-tailed Student's $t$ test was used ${ }^{*}, P<0.05$ and ${ }^{*}, P<0.01$; Supplemental Data Set 3$)$. ns, nonsignificant.

(C) Representative images of DR5:GUS staining of root tips (top) and emerging lateral roots (bottom) from two independent lines stably transformed with DR5:GUS in R108 or cra2-8. Germinated seedlings were grown in Fåhraeus medium containing 0.25 or $10 \mathrm{mM} \mathrm{KNO}_{3}$ for $10 \mathrm{~d}$. Images were acquired with an Olympus microscope equipped with an interference device. Bars $=100 \mu \mathrm{m}$.

(D) Free IAA content in the roots of cra2T-4 and R108 grown with 0 or $10 \mathrm{mM} \mathrm{KNO}_{3}$ for $7 \mathrm{~d}$. The data are means \pm sD of three independent pools of roots, and significant differences were determined with an ANOVA with a posthoc Tukey's test, as indicated by letters $(P<0.05$; Supplemental Data Set 3$)$.

domain) recombinant protein was performed, revealing a radioactive band when incubated with $\mathrm{MgCl}_{2}$ and $\mathrm{MnCl}_{2}$ (Figure $6 \mathrm{~A}$ ). This revealed that the MtCRA2 receptor has an autophosphorylation kinase activity at least in vitro. To confirm the kinase activity of MtCRA2 in vivo, a Pro35S:MtCRA2-FLAG-HA (the FLAG-HA was fused to the C-terminal end of CRA2) construct was stably transformed into the cra2-8 mutant, and pCAMBIA1307 empty vector was transferred into R108 as a control. Such ectopic expression of MtCRA2-FLAG-HA was sufficient to rescue the compact root architecture phenotype of cra2 (Supplemental Figure 13). Phospho-tag immunoblot assays revealed that a majority of the MtCRA2 protein pool in the roots and shoots of cra2/ Pro35S:CRA2-FLAG-HA complemented plants remained in an unphosphorylated state and that only a minor proportion of the MtCRA2 pool was potentially phosphorylated under the MtCEP1 nontreated conditions (Figure 6B). This putative MtCRA2 phosphorylated band was lost upon a calf intestinal alkaline phosphatase (CIAP) treatment (Figure 6B), demonstrating the phosphorylated status of MtCRA2. When treated with MtCEP1 peptides, the proportion of the MtCRA2 phosphorylated form increased at $0.5 \mathrm{~h}$ in roots and at $6 \mathrm{~h}$ in shoots (Figures $6 \mathrm{~B}$ and $6 \mathrm{C}$ ). These kinase assays performed both in vitro and in vivo indicate that MtCRA2 is a functional kinase with an activity induced by the proposed ligand MtCEP1 peptide (Mohd-Radzman et al., 2016). These results further allowed investigating which target proteins could be phosphorylated by the MtCRA2 receptor-like kinase. 

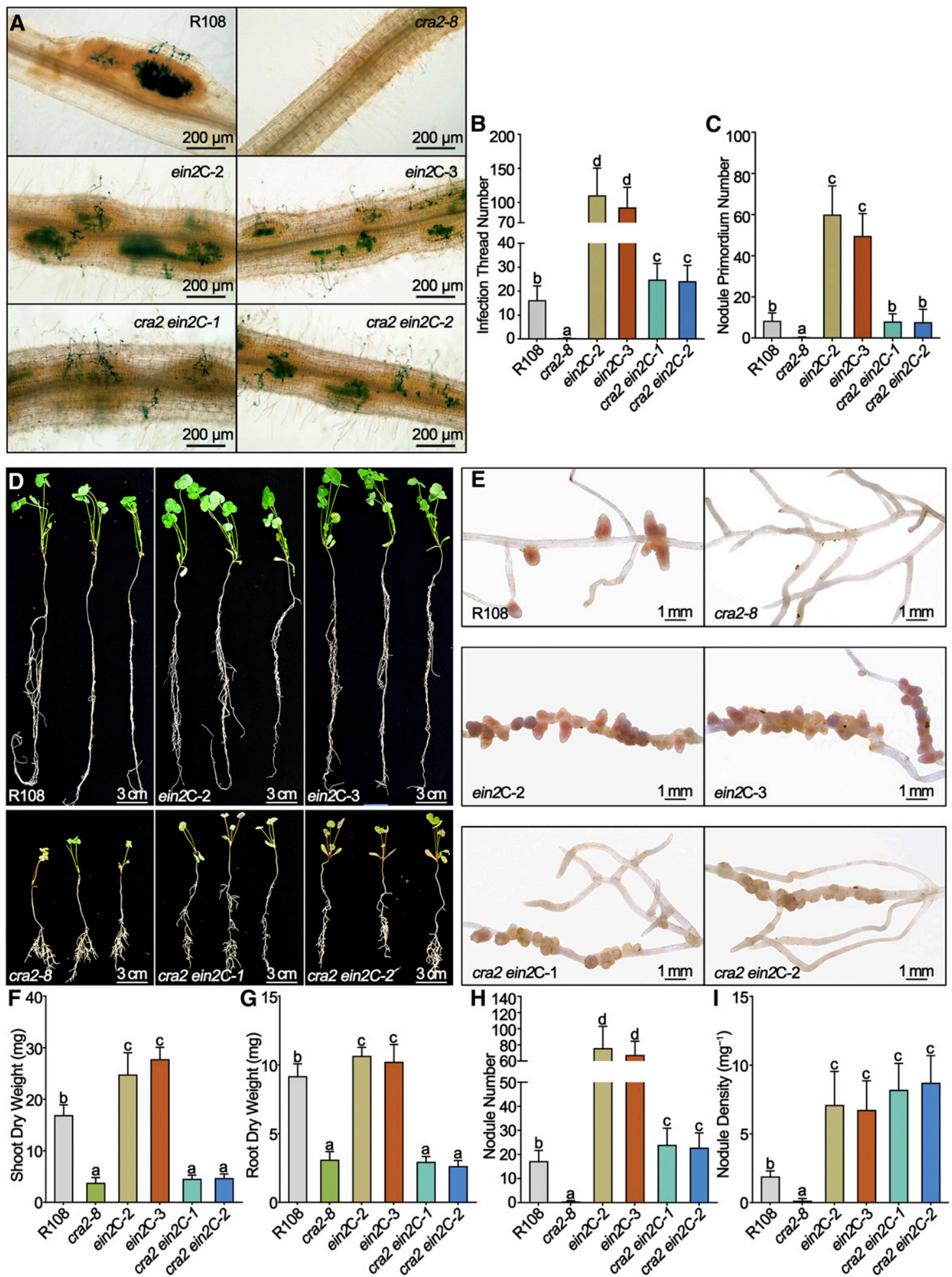

Figure 5. The Mutation of MtEIN2 Rescues the Symbiotic Nodulation of the cra2 Mutant.

(A) to (C) Early infection events of R108, cra2, ein2C, and cra2 ein2C inoculated with an Sm1021 strain carrying a ProHemA:LACZ fusion at 5 DAI. Representative images of infection threads and nodule primordia (A) and the quantification of infection threads (B) and of nodule primordia (C) are shown. Similar results were obtained in three independent experiments. The data are means \pm SD from one representative experiment, and significant differences were determined with a Kruskal-Wallis statistical test, as indicated by letters $(P<0.05, n=15$; Supplemental Data Set 3$)$. 
A quantitative phosphoproteomic approach was then comparatively applied for the roots and shoots of cra2 and R108. In total, 1353 and 1614 unique phosphopeptides (the phosphopeptide enrichment efficiency was $75 \%$ in cra2 roots, $64 \%$ in cra2 shoots, $77 \%$ in $\mathrm{R} 108$ roots, and $60 \%$ in $\mathrm{R} 108$ shoots) belonging to 872 and 980 phosphoproteins were identified in the roots and shoots, respectively. Among these, 40 and 58 phosphopeptides corresponding to various proteins, including protein kinases, E3 ubiquitin ligases, $A B C$ transporters, and transcription factors, were more abundant ( $\geq 1.5$-fold threshold) in $\mathrm{R} 108$ roots and shoots than in cra2 (Supplemental Data Set 1). Interestingly, the MtEIN2 peptides containing the Ser ${ }^{643}$ phosphorylation sites showed a decreased abundance in cra2 roots (Supplemental Figures 14 and 15A), and a second MtEIN2 phosphorylation site, Ser ${ }^{924}$, was also slightly enriched in $\mathrm{R} 108$ root but showed a very low intensity in tandem mass spectrometry (MS-MS) spectra (Supplemental Figure 15B). Interestingly, these two phosphorylation sites are conserved between MtEIN2 and AtEIN2 and were shown to be required in Arabidopsis for AtEIN2-dependent ethylene signaling (Ju et al., 2012).

\section{MtCRA2 Interacts with and Phosphorylates MtEIN2 at Ser 643 and Ser ${ }^{924}$}

An in vitro phosphorylation assay was used to test whether the phosphorylation of MtEIN2 could be directly mediated by MtCRA2. MtEIN2CT-His (corresponding to the $C$ terminus of MtEIN2 fused to a His tag) incubated with GST-MtCRA2 ${ }^{\mathrm{KD}}$ revealed that the kinase domain of MtCRA2 can phosphorylate MtEIN2 ${ }^{\mathrm{CT}}$-His in vitro (Figure 6D). A site-directed mutagenesis approach was used to validate the MtCRA2-dependent phosphorylation of MtEIN2 by changing $\mathrm{Ser}^{643}$ and Ser ${ }^{924}$ residues to

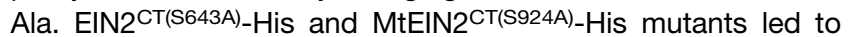
weaker autoradiographic bands than that of MtEIN2 ${ }^{\mathrm{CT}}$-His, and the autoradiographic band intensity of MtEIN2CT(S643A)-His was

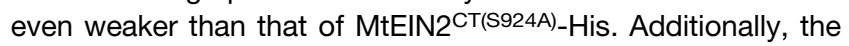
double Ser-Ala mutant MtEIN2 ${ }^{\mathrm{CT}(\mathrm{AA})}$-His did not reveal any phosphorylated band (Figure 6E). These results indicate that MtCRA2 can phosphorylate MtEIN2 in vitro at the Ser ${ }^{643}$ and Ser ${ }^{924}$ positions and that $\mathrm{Ser}^{643}$ may be more actively phosphorylated by MtCRA2 than Ser ${ }^{924}$.

To evaluate the interaction between MtCRA2 and MtEIN2, different experiments were performed. First, GST pull-down assays were performed with GST-MtCRA2 ${ }^{\mathrm{KD}}$ and MtEIN2 ${ }^{\mathrm{CT}}$-His in Escherichia coli BL21, revealing an association of the two proteins (Figure 7A). Second, a yeast two-hybrid assay revealed that ADMtCRA2 ${ }^{\mathrm{KD}}$ interacted with BK-MtEIN2 ${ }^{\mathrm{CT}}$ (Figure 7B). Third, a firefly luciferase complementation imaging assay in Nicotiana benthamiana leaves also demonstrated that the full-length
MtCRA2-nLUC and MtEIN2-cLUC proteins could interact with each other (Figure 7C). Overall, these results suggest that by using different heterologous and in vitro systems, MtCRA2 can interact with and transphosphorylate MtEIN2 at the Ser643 and Ser924 positions.

\section{MtCRA2 Additionally Locally Regulates Infection in the Root by Preventing the Cleavage of MtEIN2}

To determine the subcellular localization of MtEIN2 and MtCRA2, Pro35S:CRA2-GFP and Pro35S:EIN2-GFP constructs were first transiently coexpressed with different membrane markers using agroinfiltration in $N$. benthamiana leaves. The green fluorescence of MtEIN2-GFP and MtCRA2-GFP fusion proteins merged with the red fluorescence of the RFP-HDEL endoplasmic reticulum (ER) marker (Figures 7D and 7F; Supplemental Figures 16A and 16C). In addition, the MtCRA2-GFP fusion also merged with the CALCINEURIN B-LIKE1 (CBL1)-RFP plasma membrane (PM) marker, whereas MtEIN2-GFP did not (Figures 7E and 7G; Supplemental Figures 16B and 16D). Overall, these results indicate that in $N$. benthamiana mesophyll cells, MtCRA2 localizes in the ER and PM while MtEIN2 only localizes in the ER. Second, a colocalization experiment was additionally performed in $N$. benthamiana leaves, revealing that the MtEIN2-RFP fusion colocalizes with the MtCRA2-GFP fusion in heterologous systems (Figure $7 \mathrm{H}$; Supplemental Figure 16E).

Finally, because previous reports showed that the phosphorylated status of AtEIN2 influences the stability of its C-terminal end in Arabidopsis, consequently inhibiting ethylene signaling (Ju et al., 2012), we examined in R108 and cra2 roots using an immunoblot test the stability of the Pro35S:MtEIN2-HA fusion after a 24-h treatment with 5 or $50 \mu \mathrm{M}$ 1-aminocyclopropane-1-carboxylic acid (ACC). Consistent with results gained in Arabidopsis (Wen et al., 2012), the ACC treatment indeed induced the cleavage of the $\mathrm{C}$ terminus of MtEIN2 into several fragments in $M$. truncatula roots (Supplemental Figure 17A). A quantitative assay revealed that the ratio between the full-length MtEIN2-HA fusion and the hydrolyzed fragments was lower in cra2 than in R108 under nontreated and ACC $(5 \mu \mathrm{M})$ conditions. Furthermore, the $50 \mu \mathrm{M}$ ACC treatment led to the cleavage of almost all of the MtEIN2 pool in both R108 and cra2 roots (Supplemental Figure 17B). Interestingly, low-N conditions or MtCEP1 peptide treatment repressed the cleavage of MtEIN2 in R108 roots, whereas the MtEIN2 full-length protein pool was not affected in cra2 roots (Figures $7 \mathrm{I}$ and $7 \mathrm{~J}$ ). These results indicate that low-N MtCEP1dependent signaling can partially inhibit the cleavage of the C-terminal end of MtEIN2 depending on the MtCRA2 receptor.

Previous studies revealed that root nodulation is regulated systemically from shoots by the MtCRA2 pathway (Huault et al.,

Figure 5. (continued).

(D) to (I) Shoot and root growth and nodulation phenotype of R108, cra2, ein2C, and cra2 ein2C inoculated with Sm1021 after 1 week of growth in a soil/ vermiculite mixture with Fåhraeus medium and then allowed to grow for 3 weeks. Representative images of whole plants (D) and nodulated roots (E) and quantification of the shoot dry weight (F), root dry weight (G), nodule number (H), and nodule density (nodule number relative to the root dry weight; [I]) are shown. Similar results were obtained in three independent experiments. Data are means \pm SD from one representative experiment, and significant differences were determined with a Kruskal-Wallis statistical test, as indicated by letters $(P<0.05, n=15$; Supplemental Data Set 3 ). 
A

A

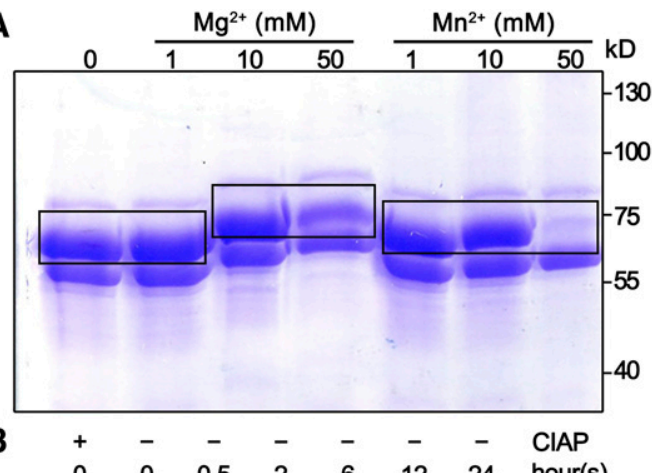

$\begin{array}{ccccccccc}\mathrm{B} & + & - & - & - & - & - & - & \mathrm{CIAP} \\ & 0 & 0 & 0.5 & 2 & 6 & 12 & 24 & \text { hour(s) }\end{array}$
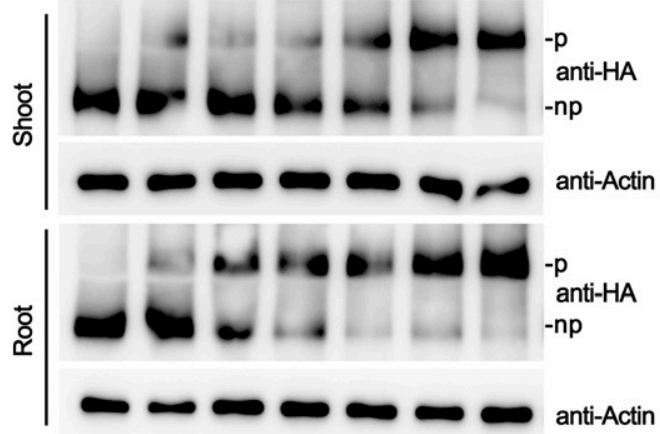

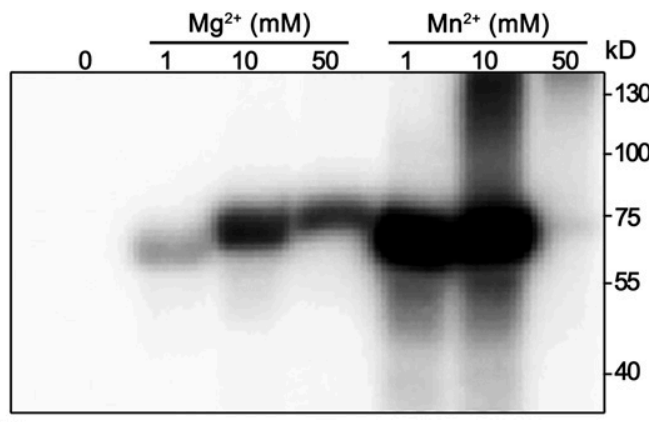

C

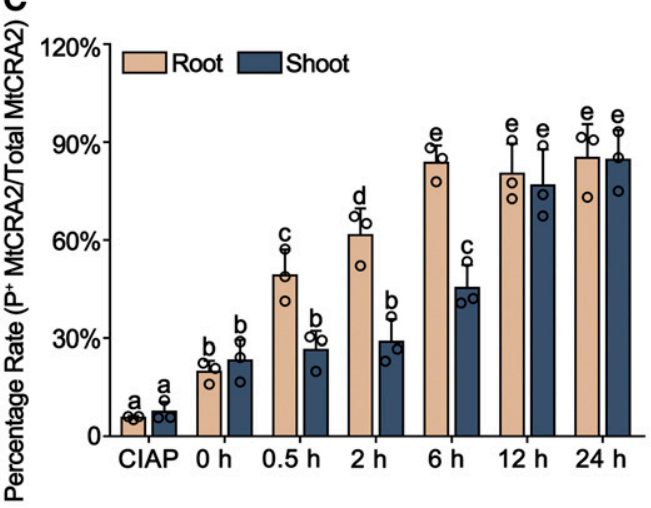

D

E
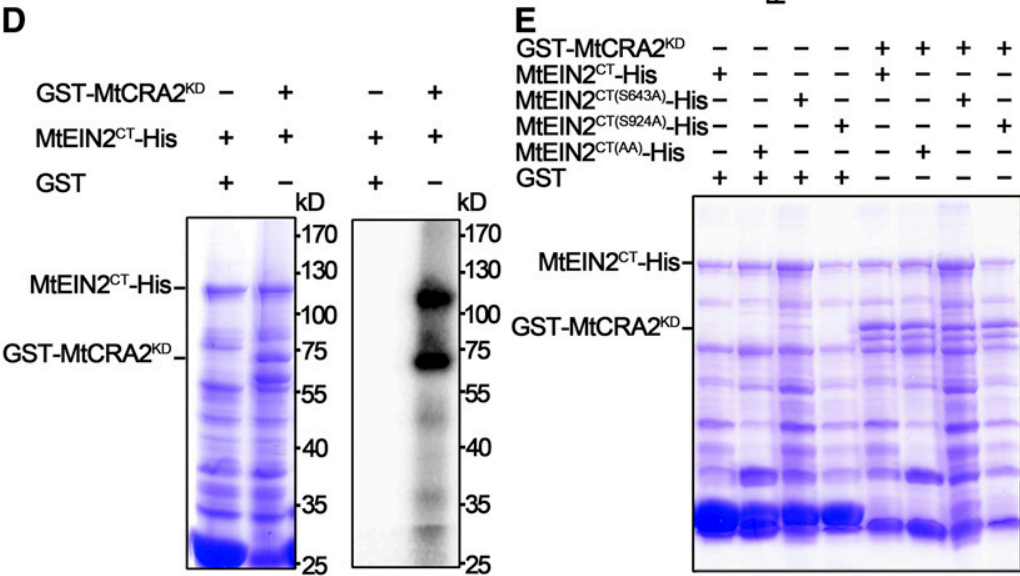

$-$\begin{tabular}{llllll}
\hline & - & + & + & +
\end{tabular}

$+---+--$

$-+---+$

$---+---+$

$-+---+-$

$++++---$

GST $^{\text {GT(AA)-HiS }}++\overline{+}+\overline{+}+-$

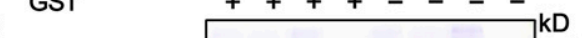
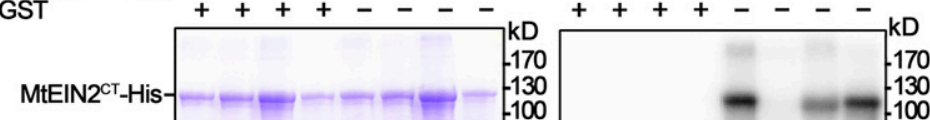

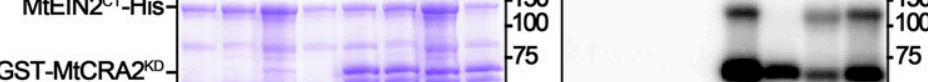
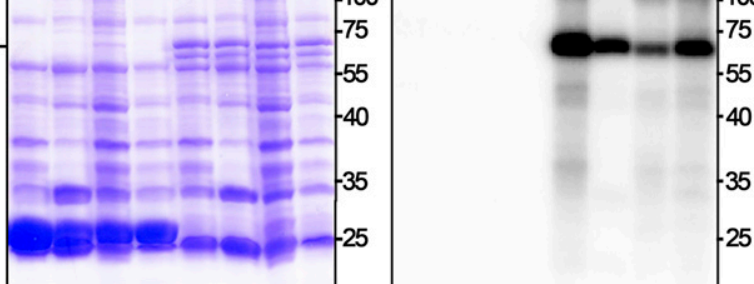

55

$-40$

$-35$

$-25$

Figure 6. The MtCRA2 Kinase Can Be Activated by MtCEP1 Peptides and Phosphorylates MtEIN2 on Ser ${ }^{643}$ and Ser ${ }^{924}$.

(A) The autophosphorylation kinase activity of a purified MtCRA2 kinase domain fusion with GST (GST-MtCRA2 ${ }^{\mathrm{KD}}$ ) was assayed in vitro with [ $\left.\gamma^{-32} \mathrm{P}\right] \mathrm{ATP}$ in a reaction buffer containing $0,1,10$, or $50 \mathrm{mM} \mathrm{Mg}^{2+}$ or $\mathrm{Mn}^{2+}$. Protein loading was visualized by Coomassie Brilliant Blue staining (left), with MtCRA2 ${ }^{\mathrm{KD}}$ bands indicated by the rectangular boxes. Radioactive signals (right) were detected with a phosphorimager.

(B) and (C) The effects of MtCEP1 on the MtCRA2 autophosphorylation kinase activity were assayed by Phos-tag immunoblotting.

(B) Phos-tag immunoblots of proteins extracted from the roots and shoots of cra2/Pro35S:CRA2-FLAG-HA plants treated with MtCEP1 for 0, 0.5, 2, 6, 12, and $24 \mathrm{~h}$. Protein extracts from cra2/Pro35S:CRA2-FLAG-HA in the absence of MtCEP1 peptides were treated with the CIAP phosphatase (first lane). np, nonphosphorylated; $p$, phosphorylated.

(C) Quantification of immunoblot bands performed with ImageJ software. Values show the percentages of the phosphorylated MtCRA2 pool relative to the total MtCRA2 protein pool. The data are means \pm SD of three independent pools of roots, and significant differences were determined with an ANOVA with a posthoc Duncan's test, as indicated by letters $(P<0.05$; Supplemental Data Set 3$)$. $h$, hour(s).

(D) and (E) In vitro phosphorylation assay of the purified MtCRA2 ${ }^{\mathrm{KD}}$ fusion with a GST tag (GST-MtCRA2 ${ }^{\mathrm{KD}}$ [D]), of the MtEIN2 ${ }^{\mathrm{CT}}$ protein fusion with a His tag (MtEIN2 ${ }^{\mathrm{CT}}$-His [D]), of the MtEIN2 mutant versions mutated at conserved Ser residues (MtEIN2 ${ }^{\mathrm{CT}}(\mathrm{S} 643 \mathrm{~A})$-His and MtEIN2 ${ }^{\mathrm{CT}}(\mathrm{S} 924 \mathrm{~A})-\mathrm{His}$ [E]), and of the MtEIN2 ${ }^{\mathrm{CT}(\mathrm{AA})}$-His double mutant (E). Proteins were incubated together in a kinase reaction buffer with [ $\left.\gamma-{ }^{32} \mathrm{P}\right] A T P$ and were then separated by SDS-PAGE. Protein loading was visualized by Coomassie Brilliant Blue staining (left), and radioactive signals (right) were detected with a phosphorimager. 


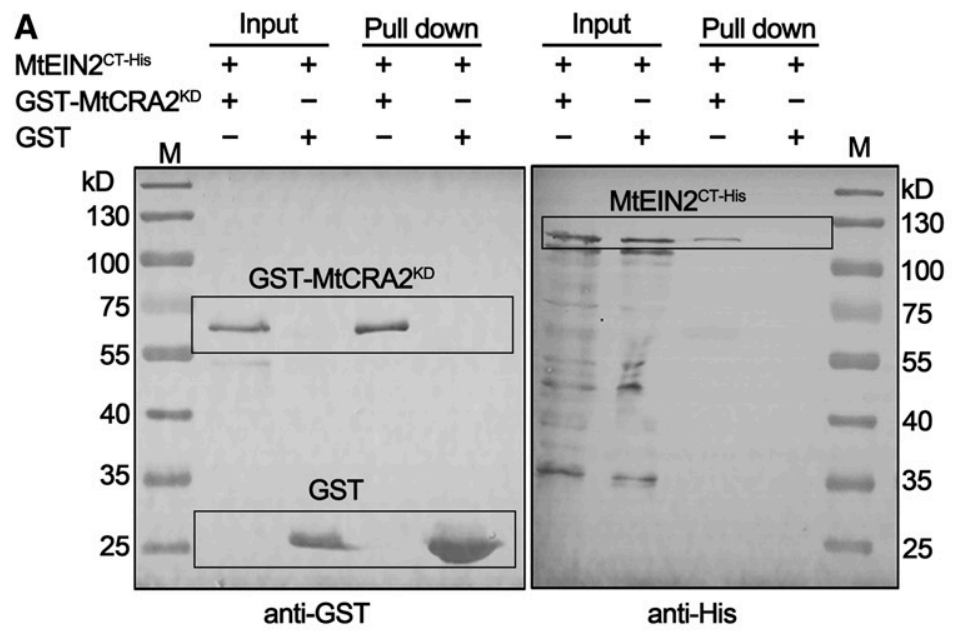

B

B
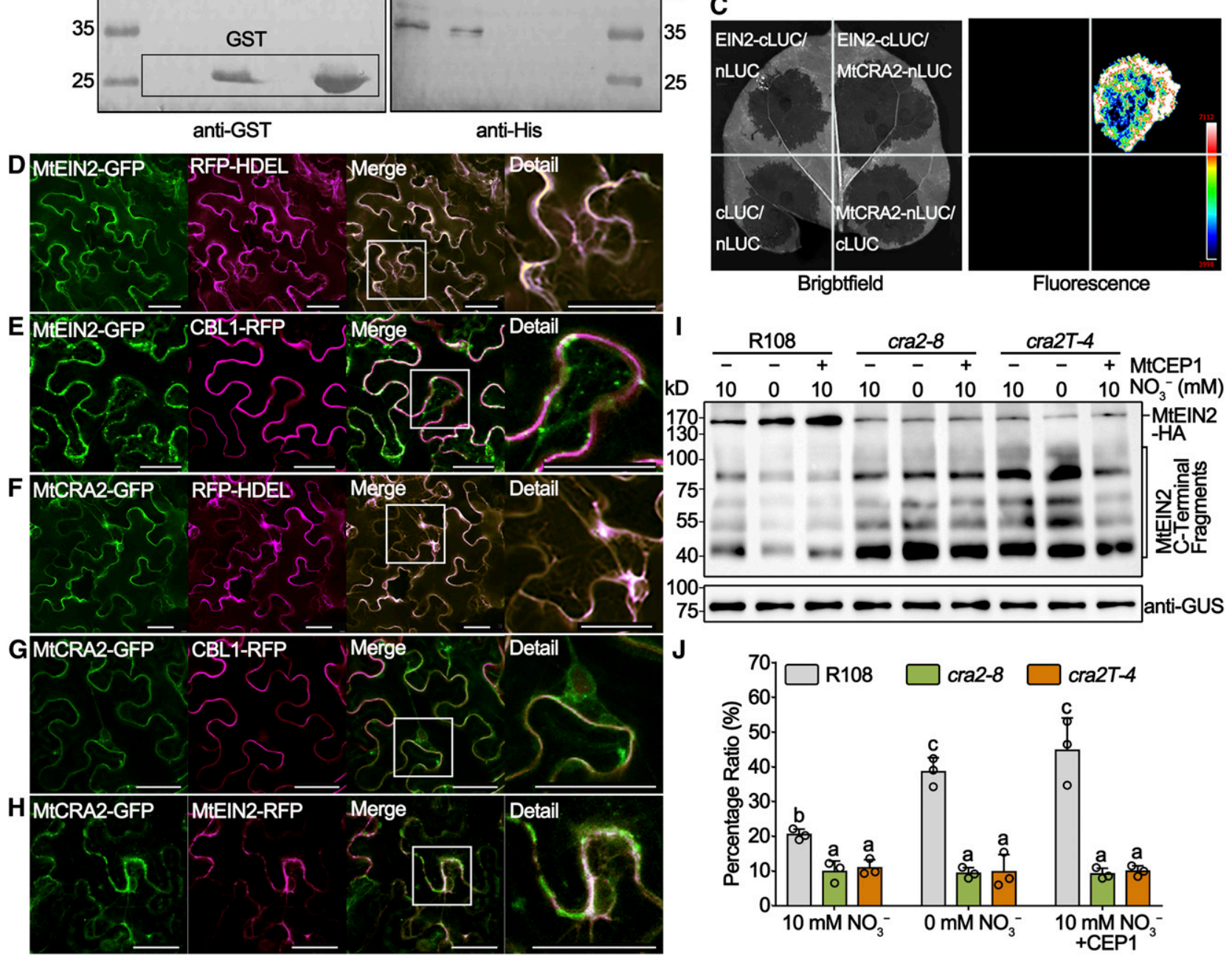

Figure 7. MtCRA2 Interacts with MtEIN2 and Inhibits Its Cleavage.

(A) GST pull-down assay of GST-MtCRA2 ${ }^{\mathrm{KD}}$ and MtEIN2 ${ }^{\mathrm{CT}}$-His fusion proteins coexpressed in BL21 E. coli cells. An immunoblot analysis with anti-GST (left image) and anti-His antibodies (right image) allowed the identification of input and pull-down proteins, respectively. Proteins corresponding to the bands observed are indicated with the rectangular boxes.

(B) Yeast two-hybrid assay of the MtCRA2 ${ }^{\mathrm{KD}}$ and MtEIN2 ${ }^{\mathrm{CT}}$ protein interaction in AH109 cells grown on SD/-Leu/-Trp (top) and SD/-Ade/-His/-Leu/-Trp (middle and bottom) media. pGBKT7-p53/pGADT7-RecT and pGBKT7/pGADT7 vectors were used as positive and negative controls, respectively.

(C) Firefly luciferase complementation imaging assay of the interaction between full-length MtCRA2 and MtEIN2 proteins in N. benthamiana leaves. Luciferase fluorescence was detected using a CCD camera.

(D) to (H) Subcellular localization of MtCRA2 and MtEIN2. For the localization of MtEIN2 and MtCRA2, N. benthamiana leaves were cotransformed with Pro35S:MtEIN2-GFP and the Pro35S:RFP-HDEL fusion used as an ER marker (D) or Pro35S:CBL1-RFP fusion used as a PM marker (E), Pro35S:MtCRA2GFP and Pro35S:RFP-HDEL (F), or Pro35S:CBL1-RFP (G). For the MtCRA2 and MtEIN2 colocalization, N. benthamiana leaves were cotransformed with 
2014; Laffont et al., 2019), whereas it is locally regulated by MtEIN2 within roots (Prayitno et al., 2006). To further test whether a local function of MtCRA2 may additionally exist in roots to regulate nodulation, a CRISPR/Cas9 strategy was used for root transformation to generate R108/cra2C and R108/ein2C composite plants with wild-type shoots and mutant roots (Supplemental Figures $18 \mathrm{~A}$ to $18 \mathrm{C}$ ). The infection thread numbers were quantified in R108/R108, R108/cra2C, and R108/ein2C plants, and consistent with the hyperinfection phenotype of the stable einC mutant, an increased number of infection threads was observed at $4 \mathrm{DAl}$ in R108/ein2C roots compared with the R108/R108 control, and there were significantly fewer infection threads in R108/cra2 roots than in R108/R108 roots (Figures $8 \mathrm{~A}$ to $8 \mathrm{C}$ ). The MtCEP1 peptide treatment significantly increased the number of infection threads in R108/R108 and R108/cra2C plants, in agreement with a role of MtCRA2 in shoots (Huault et al., 2014; Laffont et al., 2019), but not in R108/ein2C plants compared with untreated controls, suggesting a local function of EIN2/SKL in roots downstream of MtCEP1/MtCRA2 as previously proposed (Mohd-Radzman et al., 2016). MtCEP1 caused a more than threefold increase in the infection thread number in R108/R108, whereas only a 1.7-fold increase was observed in R108/cra2C plants (Figures $8 \mathrm{~A}$ to $8 \mathrm{C}$ ). These results indicated that the mutation of MtCRA2 in the root significantly reduces the promoting effect of MtCEP1 peptides on rhizobial infections, suggesting that a local role of MtCRA2 may additionally exist in roots to regulate rhizobial infections. Overall, these results suggest that the MtCRA2-mediated transphosphorylation of MtEIN2 negatively affects the protein pool of this ethylene signaling component, which is a key inhibitor of early symbiotic nodulation, to maintain rhizobia susceptibility locally in roots.

\section{DISCUSSION}

The signaling pathways and molecular mechanisms that coordinate the development of lateral roots and symbiotic nodules in legume roots remain poorly understood. MtCEP1 peptides acting through the presumptive MtCRA2 receptor-like kinase were previously reported to antagonistically regulate the lateral roots locally from root and nodule formation systemically from shoots (Huault et al., 2014), which is in agreement with phenotypic data reported here. In this study, the phenotype complementation of cra2 by MtCRA2 confirmed the role of MtCRA2 in regulating both lateral root and nodule number, and a transcriptomic analysis of the cra2 mutant revealed that the MtCRA2 pathway promoting early nodulation regulates the NF signaling symbiotic pathway, as was also recently shown for Jemalong A17 cra2 mutants (Laffont et al., 2019). Consequently, the MtCEP1/MtCRA2 pathway promotes infection thread and nodule primordia formation under low$\mathrm{N}$ conditions, consistent with previous studies by Imin et al. (2013) and Laffont et al. (2019). To further functionally link MtCEP1 to the MtCRA2 receptor, we now showed that these signaling peptides can trigger the MtCRA2 receptor-like kinase activity. The MtCRA2 receptor-like kinase can additionally transphosphorylate MtEIN2 at the Ser ${ }^{643}$ and Ser ${ }^{924}$ positions, leading to the repression of the cleavage of MtEIN2 and thus to an inhibition of the ethylene signaling pathway that inhibits rhizobial infections. This inhibition of the ethylene pathway by MtCRA2 would allow the active maintenance of plant susceptibility to rhizobia under low-N conditions, as previously proposed by Mohd-Radzman et al. (2016). Regarding the novel cra2 root phenotypes reported in this study compared with those described by Huault et al. (2014), we show that this mutant perceives changes in $\mathrm{N}$ environments but has altered root growth and developmental responses to these conditions. The transcriptomic analysis revealed that the root auxin metabolism and response were notably altered, and we showed more specifically that the MtCEP1/MtCRA2 pathway represses the expression of the MtYUC2 auxin biosynthesis gene. This corresponds with reduced auxin accumulation and responses in roots, which would therefore promote main root growth and inhibit lateral root formation. Taken together, these results show that MtCRA2 appears to be an integrator of various hormonal pathways to differentially regulate lateral root and nodule development in legume roots under low-N conditions (Figure 9).

The establishment and maintenance of the rhizobium-legume symbiosis involve highly regulated signal exchanges and recognition between the two partners. Rhizobium inoculation notably rapidly induces the accumulation of ethylene in roots (Larrainzar et al., 2015; Reid et al., 2018), and ethylene is a well-described inhibitor of the early stages of the rhizobium-legume symbiosis (Penmetsa and Cook, 1997). We showed that almost no infection threads or nodule primordia could be detected in cra2 compared with the R108 genotype at $5 \mathrm{DAl}$ (Figures 1D to 1G), indicating that rhizobial infection is primarily blocked in cra2. The few nodules formed at $21 \mathrm{DAl}$ in cra2 roots (Figures $1 \mathrm{~A}$ to $1 \mathrm{C}$ ) may have originated through crack entry and/or corresponded to strongly delayed/impaired root hair infections. In agreement with the MtCRA2 function in regulating rhizobial infections, we showed that the cra2 ein $2 C$ double mutant exhibits a partially rescued level of rhizobial infections, primordia formation, and nodule numbers (Figure 5). Accordingly, Mohd-Radzman et al. (2016) showed that the nodule number of cra2 mutants treated with the aminoethoxyvinylglycine (AVG) ethylene inhibitor was partially rescued,

Figure 7. (continued).

Pro35S:MtCRA2-GFP and Pro35S:MtEIN2-RFP constructs $\mathbf{( H )}$. Similar observations were made in more than three random views and in another independent repeat. The GFP and RFP signals were detected with a Leica SP8 confocal microscope. Bars $=40 \mu \mathrm{m}$.

(I) The cleavage of MtEIN2 was measured by immunoblot analysis in the transgenic roots of R108, cra2-8, and cra2T-4 transformed with a Pro35S:MtEIN2$H A$ construct and treated with $0 \mathrm{mM} \mathrm{N}$ or $1 \mu \mathrm{M} \mathrm{MtCEP} 1$ peptides for $24 \mathrm{~h}$. The full-length MtEIN2-HA protein (146 kD) and C-terminal fragments of MtEIN2 (40 to $100 \mathrm{kD}$ ) are indicated. The Pro35S:MtEIN2-HA construct also contains a Pro35S:GUS fusion, and GUS was used as a loading control.

(J) The quantification of the intensity of immunoblot bands, as analyzed using ImageJ software. The values show the percentages of the full-length MtEIN2 protein pool relative to the total of the MtEIN2 protein pool. The data are means \pm SD of three independent experiments based on three independent pools of roots, and significant differences were determined with an ANOVA with a posthoc Duncan's test, as indicated by letters $(P<0.05$; Supplemental Data Set 3$)$. 


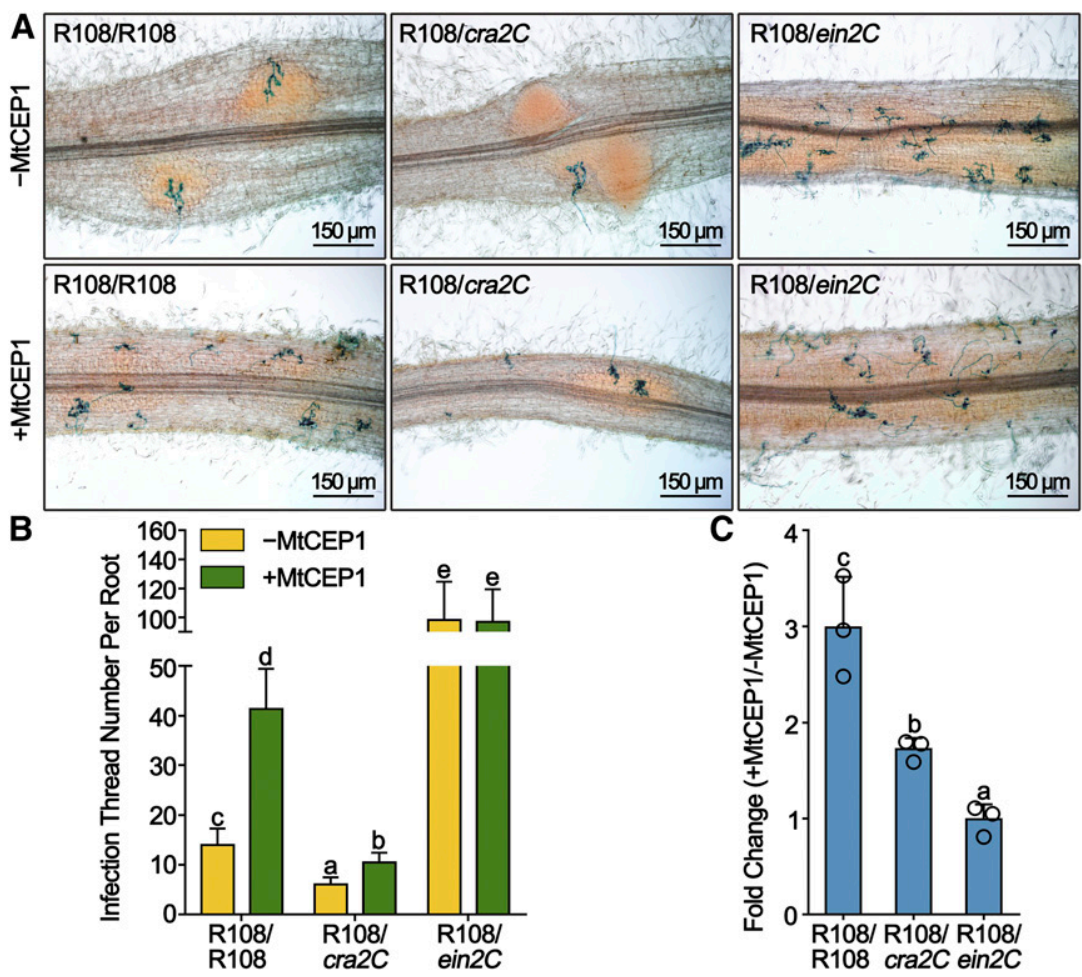

Figure 8. MtCRA2 Partially Regulates Rhizobial Infections Locally in the Root.

Early infection events are shown for R108/R108, R108/cra2C, and R108/ein2C plants transformed with CRISPR/Cas9 pHSN401-EV, pHSN401-MtCRA2, or pHSN401-MtEIN2 and inoculated with an Sm1021 strain carrying a ProHemA:LACZ fusion. The 2-week-old composite plants were transferred to Fåhraeus medium ( $\mathrm{N}^{-}$, with $1.5 \%$ agar) with or without $1 \mu \mathrm{M} \mathrm{MtCEP1}$ peptides for $4 \mathrm{~d}$ and then inoculated with rhizobia resuspended in sterile water with or without 1 $\mu \mathrm{M}$ MtCEP1 peptides. Representative images of infection threads (A) and the quantification of the infection threads at 4 DAl (B) are shown. In (C), values show the fold change of the infection thread number of the MtCEP1-treated plants relative to those of untreated controls. The data are means \pm SD of three independent experiments, and significant differences were determined with a Kruskal-Wallis statistical test, indicated by letters $(P<0.05, n=30$; Supplemental Data Set 3).

and no significant changes in ethylene levels were detected between cra2 and R108, prompting the suggestion that MtCEP1 peptides may repress ethylene signaling in an MtCRA2dependent manner to promote rhizobial infections and nodulation (Mohd-Radzman et al., 2016). Fewer infections were observed in cra2 ein $2 C$ versus ein2, which may be indirectly due to the strong root phenotype of cra2 but may also suggest that CRA2independent pathway(s) may additionally trigger EIN2 in cra2 to partially regulate the number of infections.

In this study, a molecular link was established between MtCRA2 and ethylene signaling pathways through the observation that the MtCRA2 receptor-like kinase can transphosphorylate the MtEIN2 ethylene signaling factor at $\operatorname{Ser}^{643}$ and $\operatorname{Ser}^{924}$ (Figures 6D and 6E). These phosphorylation sites are conserved with AtEIN2 and are critical to regulate its stability and therefore the ethylene signaling output (Ju et al., 2012). MtCRA2 colocalizes with MtEIN2 in the ER when ectopically overexpressed in heterologous systems and prevents its cleavage in $M$. truncatula roots (Figures 7D to $7 \mathrm{~J}$ ). The MtEIN2 localization was anticipated, as AtEIN2 also is located in the ER in Arabidopsis (Ju et al., 2012). Perhaps more unexpectedly, the MtCRA2 subcellular localization was detected in both the PM and ER membranes. Such subcellular localization patterns were previously observed for other LRR-RLKs involved in signaling peptide perception (Guo et al., 2010; Li et al., 2015). Indeed, in L. japonicus and M. truncatula, CLAVATA1 (CLV1), CLV2, FERONIA, and CRN were localized in variable proportions at the PM and on the ER (Krusell et al., 2011; Li et al., 2015; Crook et al., 2016). Compared with the LRR-RLKs localized at the PM, how the LRR-RLKs localized in the ER could be activated by secreted signaling peptides and then phosphorylate downstream target proteins (Guo et al., 2010) remains to be established.

We showed that the phosphorylation of MtCRA2 is quickly activated in roots by a 30-min MtCEP1 peptide treatment and slowly activated in shoots by a 6-h MtCEP1 peptide treatment, meaning that MtCEP1 and MtCRA2 can interact both in roots and in shoots. The low nodule number of the cra2 mutant is rescued to the wild-type level in the cra2 ein $2 \mathrm{C}$ double mutant. Previous studies revealed that root nodulation regulation is systemically mediated by the MtCRA2 pathway from shoots (Huault et al., 2014; Laffont et al., 2019) while it is locally controlled by MtEIN2 within roots (Prayitno et al., 2006). In this study, we now show that the mutation of MtCRA2 only in roots was sufficient to reduce the number of infection threads and that the positive regulation of MtCEP1 peptides on rhizobial infection was partially dependent of 


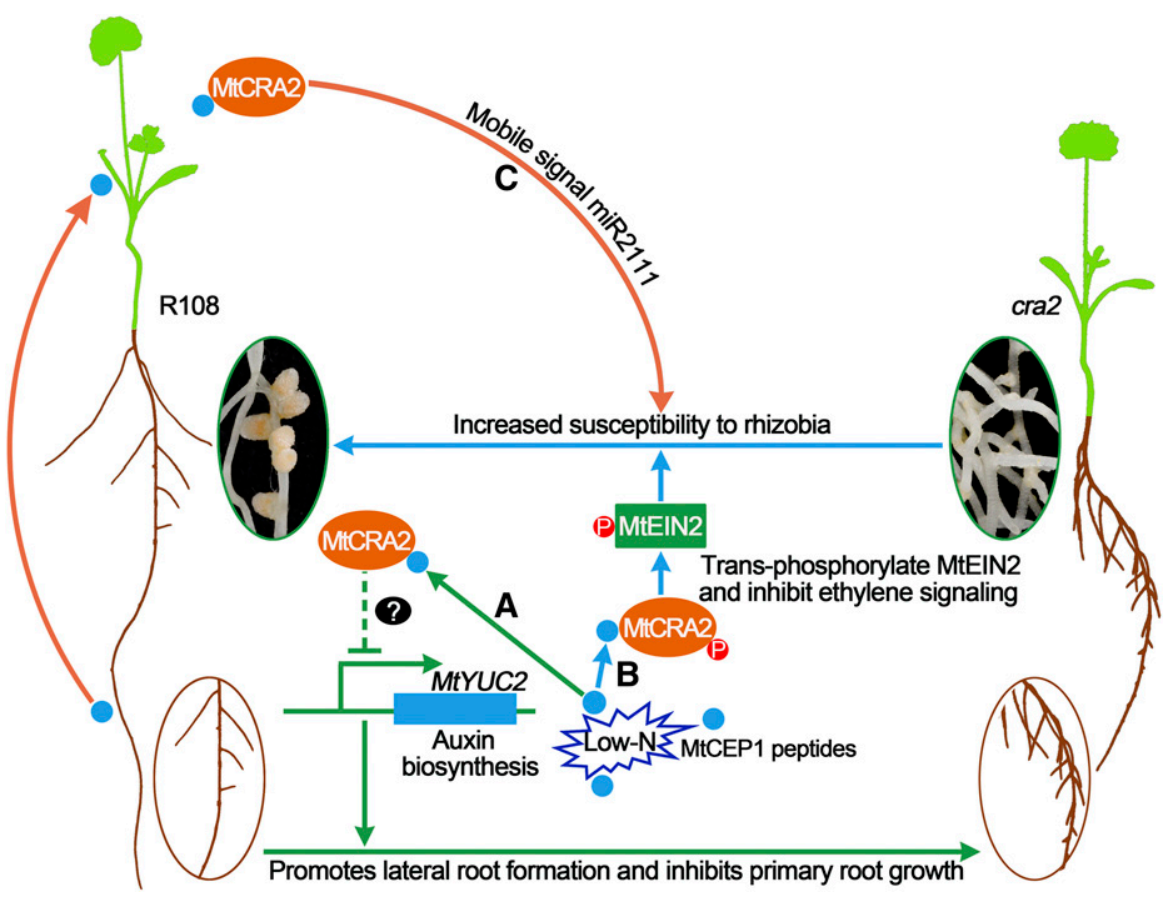

Figure 9. Model for the Action of MtCRA2 in Coordinating Root Architecture and Symbiotic Nodulation under Low-N Conditions.

MtCEP1 expression is induced under $\mathrm{N}$-starvation conditions, and the encoded signaling peptides activate the MtCRA2 receptor-like kinase. In pathway $\mathrm{A}$, MtCRA2 locally represses transcript levels of the MtYUC2 auxin biosynthesis gene in the root via an unknown pathway, leading to a decrease in auxin biosynthesis and response and allowing for the modulation of root architecture. In pathway B, on the other hand, when plants are inoculated with rhizobia, ethylene biosynthesis is rapidly induced and promotes the cleavage of MtEIN2, thus activating the ethylene signaling pathway that inhibits rhizobial infection. Under low-N conditions, the MtCEP1-activated MtCRA2 pathway may phosphorylate MtEIN2 and repress ethylene signaling locally in roots, offsetting the inhibitory effect of ethylene on rhizobial infection. In addition to these local pathways acting in roots, MtCEP1 peptides move from roots to shoots and then induce mobile signals including miR2111 that travel from the shoot to the root and function downstream of MtCRA2 to promote nodulation (pathway C). P, phosphate group.

MtCRA2 in roots (Figures 8 A to $8 \mathrm{C}$ ). In addition, similar to previous results obtained using grafting, we show that SKL negatively regulates infection threads locally from roots and that the skl mutation in roots was sufficient to impede the effect of MtCEP1 peptides on infection threads (Prayitno et al., 2006; MohdRadzman et al., 2016). R108/ein2C plants also presented the typical hyperinfection phenotype of the skl mutant and also could not mediate the MtCEP1-induced regulation of infection thread number (Figures $8 \mathrm{~A}$ to $8 \mathrm{C}$ ). Overall, these results suggest that MtCRA2 may also partially regulate nodulation locally in roots by transphosphorylating MtEIN2. However, an alternative interpretation is that, despite the direct interaction and transphosphorylation of MtEIN2 by MtCRA2 identified herein, other unknown kinase(s) activated under low-N conditions in $M$. truncatula roots may indirectly fulfill this activity. As the MtCRA2 function in roots is associated with the regulation of RSA (Huault et al., 2014; Laffont et al., 2019), this suggests that the MtCRA2MtEIN2 interaction may also have a function in root development. Indeed, the cra2 ein $2 \mathrm{C}$ mutant has longer roots and a lower lateral root density than those of the cra2 mutant. Further investigations are needed to explore which downstream targets of the MtCRA2 pathway are recruited in shoots to drive the systemic regulation of root nodulation. A recent study notably identified that miR2111 is a systemic effector acting downstream of MtCRA2 to promote nodulation (Gautrat et al., 2020).

In this study, we additionally showed that the MtCEP1/MtCRA2 pathway inhibits MTYUC2 expression as well as auxin biosynthesis and the auxin response in roots under low- $\mathrm{N}$ conditions, thereby modulating root growth and branching (Figures 2 to 4). Previous reports have shown that lateral root elongation is promoted under $\mathrm{N}$-deficiency conditions by the upregulation of various auxin biosynthesis genes, such as AtTAR2 (TRYPTOPHAN AMINOTRANSFERASE RELATED2), AtYUC5, AtYUC8, and AtTAR3, that stimulate root growth (Ma et al., 2014; Yu et al., 2014). Our data show that MIYUC2 expression is partially affected by $\mathrm{N}$ starvation in cra2 (Figure $4 \mathrm{~A}$ ), meaning that, rather than the CEP1-CRA2 pathway, other pathway(s) could regulate MtYUC2 expression, depending on $\mathrm{N}$ availability. Modulation of the auxin content and response thus acts as a mediator to adjust the root growth and branching depending on $\mathrm{N}$ availability. The findings of Yendrek et al. (2010) and our results show that the root length of $M$. truncatula R108 is longer, and that the lateral root density is reduced without $\mathrm{NO}_{3}{ }^{-}$or $\mathrm{NH}_{4}{ }^{+}$, compared with the $10 \mathrm{mM} \mathrm{NO}_{3}{ }^{-}$or $\mathrm{NH}_{4}{ }^{+}$conditions. Interestingly, cra2 has the opposite root architecture phenotype (Figure 1). As the YUC inhibitory BBo treatment and the cra2 yuc $2 \mathrm{C}$ double mutant could not completely rescue 
the root phenotypes of cra2 (Figure 3), other YUC-independent pathway(s) may exist. As the transcriptomic analysis was performed to simultaneously identify cra2-deregulated genes acting in the regulation of roots and nodules, the time point selected was not specifically targeted to the lateral root initiation stage. Refined transcriptomic analyses focused on this developmental process combined with a time-point series may likely allow pinpointing additional auxin-related genes involved. It is also anticipated that other signaling peptide/receptor-like kinases regulate RSA in addition to the CEP/CRA2 pathway, depending on $\mathrm{N}$ availability, such as those involving CLE peptides (Okamoto et al., 2009; Araya et al., 2014; Forde, 2014). No evidence that the observed MtCRA2 regulation of acropetal polar auxin transport strongly impacts lateral root number could be established (Supplemental Figures $5 \mathrm{C}$ to $5 \mathrm{~F}$ ), even though polar auxin transport may contribute to shaping other aspects of legume root architecture, as previously proposed in M. truncatula for the CLE/SUNN AON pathway (Jin et al., 2012). The increased acropetal polar auxin transport might, however, be related to the MtYUC2 upregulation observed in cra2. Recently, acropetal polar auxin transport and shoot auxin levels were shown to modulate RSA systemically from shoots depending on MtCRA2 by regulating the angle of lateral root emergence relative to the gravity vector (Chapman et al., 2020).

Overall, our results showed that MtCRA2 regulates nodulation via ethylene signaling and root growth and lateral root formation via auxin biosynthesis. Although the expression of MtYUC2 was not affected significantly in the ein $2 C$ mutant, we do not exclude the possibility that crosstalk between the auxin and ethylene pathways may exist downstream of the MtCEP1/MtCRA2 pathway. Accordingly, and as discussed previously, the cra2 ein2C double mutant has longer roots and a lower lateral root density than cra2, even though it does not rescue the compact root architecture phenotype of cra2 (Figure 5; Supplemental Figures 11E to $11 \mathrm{H})$. The expression of several MtPIN genes is increased in cra2 compared with $\mathrm{R} 108$, as is the acropetal polar auxin transport activity in roots (Supplemental Figure 5A). Knowing that in Arabidopsis ethylene regulates auxin transport by repressing the expression of PIN2 (Miao et al., 2018), it is possible that MtCRA2 regulates the expression of at least a subset of PIN genes depending on the MtEIN2 ethylene signaling pathway and, thus, acropetal polar auxin transport.

Previous studies showed that a high concentration of auxin ( $1 \mu \mathrm{M}$ IAA) can reduce the nodule numbers in $M$. truncatula and that local auxin accumulation occurs through the inhibition of polar auxin transport in response to rhizobia ( $\mathrm{Ng}$ et al., 2015; Roy et al., 2017). Moreover, TIBA rescues the low rhizobium infection and low nodulation phenotypes of the cre1 cytokinin receptor mutant, which exhibits defective auxin transport regulation in response to rhizobia ( $\mathrm{Ng}$ et al., 2015). This indicates that an early function of auxin also exists in $M$. truncatula nodulation. In this study, we show that $0.1 \mu \mathrm{M} \mathrm{NAA}$, which is enough to mimic the compact root architecture of cra2 (Figures $2 \mathrm{D}$ to $2 \mathrm{H}$ ), has no significant effect on the nodule number of R108 (Supplemental Figure 6), which is consistent with results obtained in $L$. japonicus (Maekawa-Yoshikawa et al., 2009). Accordingly, YUC inhibitor treatments could not rescue the low nodulation phenotype of cra2 (Supplemental Figure 7). We also showed that the formation of pseudonodules triggered by TIBA is independent of MTCRA2 and that this treatment could not rescue the insensitivity of cra2 to rhizobia (Supplemental Figure 8). Nodules of R108 plants treated with this low NAA concentration remained underdeveloped, suggesting that auxin may inhibit later developmental nodulation stages. As YUC2 genes were recently reported in soybean (Glycine max) and $M$. truncatula to regulate early nodulation (Schiessl et al., 2019; Wang et al., 2019), and even though our experimental conditions did not allow establishing a link between YUC genes and the MtCRA2-dependent regulation of early nodulation, potential links between YUC genes and the MtCRA2 pathway remain to be further explored.

In addition to regulating RSA and nodule organogenesis, other functions of MtCRA2 in plant adaptation to N-limited conditions were highlighted by the RNA-seq approach performed in this study. As an example, we identified several putative $\mathrm{NO}_{3}{ }^{-}$metabolic and transporter-encoding genes, including NRT2.1, whose expression was downregulated in cra2 (Supplemental Figures $3 \mathrm{C}$ and 3D). In agreement with this observation, the Arabidopsis XIP1/ CEPR1 ortholog of MtCRA2 regulates the expression of the AtNRT2.1 $\mathrm{NO}_{3}{ }^{-}$transporter-encoding gene to modulate $\mathrm{NO}_{3}$ acquisition (Huault et al., 2014; Tabata et al., 2014). Taken together, these results suggest that the regulation of $\mathrm{NO}_{3}{ }^{-}$transporters by the MtCEP1/MtCRA2 pathway to enhance $\mathrm{N}$ assimilation in roots under low- $\mathrm{N}$ conditions is likely a conserved function between legume and nonlegume plants, in addition to the recruitment of the MtCRA2 pathway to promote $\mathrm{N}$ acquisition through the induction of $\mathrm{N}$-fixing symbiotic nodulation.

\section{METHODS}

\section{Plant and Bacterial Materials and Growth Conditions}

Medicago truncatula plants used in this study are of the R108 genotype, and Tnt1 insertion mutants were screened at the Noble Foundation (Pislariu et al., 2012). Seeds were treated with $98 \%(\mathrm{v} / \mathrm{v}) \mathrm{H}_{2} \mathrm{SO}_{4}$ for $8 \mathrm{~min}$, washed three times with water, sterilized with $5 \%(\mathrm{v} / \mathrm{v})$ sodium hypochlorite for $8 \mathrm{~min}$, and then washed five times with sterile water. Seeds were placed on the surface of $0.8 \%(\mathrm{w} / \mathrm{v})$ agarose medium and stratified at $4^{\circ} \mathrm{C}$ for $3 \mathrm{~d}$, after which they were germinated at $25^{\circ} \mathrm{C}$ in the dark. All plants were grown in a greenhouse $\left(22^{\circ} \mathrm{C}, 16 / 8\right.$-h light/dark photoperiod, white fluorescent lamp [intensity of 100 to $150 \mu \mathrm{mol} \mathrm{m} \mathrm{m}^{-2} \mathrm{~s}^{-1}$ ], and 60 to $70 \%$ humidity). For seed production, plants were grown in a soil:vermiculite $(1: 3, v / v)$ mixture. For nodulation, plants were grown in a perlite:vermiculite $(2: 5, \mathrm{v} / \mathrm{v})$ mixture soaked in $\mathrm{N}$-deprived Făhraeus medium for 1 week and then inoculated with $S m 1021$ resuspended in liquid Fåhraeus medium $\left(O D_{600 \mathrm{~nm}}=0.05\right)$. For CEP1 treatment and $\mathrm{N}$ starvation experiments, plants were grown on Fåhraeus medium plates supplemented with $1.5 \%(\mathrm{w} / \mathrm{v})$ agarose covered with seed germination paper (Anchor Paper) or in liquid Fåhraeus medium supplemented with or without $\mathrm{N}$.

\section{Effects of Auxin, YUC Inhibitors, and NPA Treatments on Root Growth and Nodulation}

The auxin NAA (Sigma-Aldrich, catalog no. PH005113), the auxin transport inhibitor NPA (Sigma-Aldrich, catalog no. 33371), and the biosynthesis inhibitors Bbo (Macklin, catalog no. 5122-94-1) and PPBo (Macklin, catalog no. 51067-38-0) were used to evaluate their effects on root growth and lateral root formation. Germinated seeds were grown on plates that contained half-strength Murashige and Skoog medium (without Suc) and $1.5 \%(\mathrm{w} / \mathrm{v})$ agarose supplemented with 0.05 or $0.1 \mu \mathrm{M} \mathrm{NAA}$ or 0.5 or $1 \mu \mathrm{M}$ 
NPA or with 2, 6, or $9 \mu \mathrm{M}$ BBo for 10 d. Plates were subsequently covered with brown growth paper. For nodulation experiments, germinated seeds were grown on agarose plates covered with brown growth paper and Fåhraeus medium without $\mathrm{N}$ for $5 \mathrm{~d}$. Afterward, seedlings were transferred to new plates with Fåhraeus medium without $\mathrm{N}$ and corresponding concentrations of the aforementioned chemicals for $2 \mathrm{~d}$, after which seedlings were inoculated with $\mathrm{Sm} 1021$ resuspended in sterile water $\left(\mathrm{OD}_{600 \mathrm{~nm}}=\right.$ 0.05).

\section{Overexpression in Roots and Stable Plants}

The full-length CRA2 coding sequence (CDS) was cloned into a pCAMBIA1307-FLAG-HA vector (Zhou et al., 2014), the FLAG-HA tag was fused to the C-terminal end of CRA2, and an Agrobacterium tumefaciens EHA105 strain expressing either a Pro35S:CRA2-FLAG-HA construct or an empty vector was used to transform cra2-8 or R108, respectively. Leaves of 4week-old plants were transformed with EHA105 using the stable transformation protocol described by Gou et al. (2016).

For root transformations, the full-length MtYUC2 CDS was cloned into the pCAMBIA-2301-Pro35S-FLAG vector to generate a Pro35S:MtYUC2FLAG construct. This construct or the empty vector was then transformed into R108 using the Agrobacterium rhizogenes ARqua1 strain, as described previously by Gonzalez-Rizzo et al. (2006). Three weeks later, the transgenic roots were subjected to GUS staining used as a transformation marker based on a Pro35S:GUS cassette in the pCAMBIA-2301 vector.

\section{Mutants Generated via TALEN or CRISPR/Cas9 Approaches}

A cra2 mutant was generated using TALEN technology, based on an existing strategy decribed by $\mathrm{Ma}$ et al., (2015). We selected one target sequence (T-TATCAGCACAAACCAATC-TGAGTTTTTTTCTCTAA-TGA AAGAGTCTCTCTCAGG-A) using the TAL Effector Nucleotide Targeter 2.0 tool (https://tale-nt.cac.cornell.edu/).

The generation of a stable Mtein2 mutant and of a cra2 ein2C double mutant was based on the CRISPR/Cas9 system previously reported by Xing et al. (2014). Shortly, two target sites (target 1, GGCGGATTTAGTACA GCCTCTGG, and target 2, AGACACATAGCCAGCTCTGTGGG) were selected from the second MtEIN2 exon as well as the MtU6-1 promoter to replace the AtU6-29 promoter in the PCBC-1 vector. These two sgRNAs driven by the AtU6-26 promoter in the pHSN401 vector and the MtU6-1 promoter in the pCBC-1 vector were used, both of which were subsequently inserted into the pHSN401 vector harboring the Pro35S:Cas9NLS-FLAG construct. The cloning strategy is described in more detail by Xing et al. (2014). The mutation of CRA2 and MtEIN2 was detected in individual transgenic plants by sequencing.

For the generation of yuc2 mutant transgenic roots and yuc2 cra2 double mutant roots, the same CRISPS/Cas9 system was used. Two target sites (target 1, GCTGCTGCTGCTAATCCTGAGGG, and target 2, GGG GTGTGGAAATTCAGGCATGG) were selected. Two target sites (target 1, GCGAAACTAGGACAATCCTCCGG, and target 2, AATCAGGAAGTGTTC CTGACAGG) were selected to generate R108/cra2C transformed roots, and the same vector that was used to create the stable ein2C mutant was used to generate R108/ein2C transformed roots. Vectors were constructed as previously described and transformed into R108 or cra2 using the $A$. rhizogenes ARqua1 strain as described by Gonzalez-Rizzo et al. (2006). In brief, seedlings were incubated with ARqua1 for 1 week in half-strength Murashige and Skoog medium (without Suc) at $20^{\circ} \mathrm{C}$, transferred to a new medium (with $20 \mathrm{~g} / \mathrm{L} \mathrm{Suc} \mathrm{and} 3 \mathrm{mM} \mathrm{MES}, \mathrm{pH} 5.8$ ) for 1 week at $24^{\circ} \mathrm{C}$, and then transferred to a plate with new solidified half-strength Murashige and Skoog medium (without Suc) covered with seed germination paper for 1 week. The mutations of MtYUC2, MtCRA2, and MtEIN2 were detected in individual transgenic roots by sequencing.

\section{RNA-Seq Analysis and RT-qPCR}

Total RNA was extracted with the TRIzol reagent (Invitrogen) from roots and shoots of cra2T-4 and R108 grown in Fåhraeus medium without $\mathrm{N}$ for 1 week and then inoculated with Sm1021 for $5 \mathrm{~d}$. Three independent pools of tissue were prepared for all samples. RNA integrity was analyzed using $2 \%(\mathrm{v} / \mathrm{v})$ agarose electrophoresis assays, and quantification was performed using a NanoDrop 2000 spectrophotometer. To generate a nondirectional Illumina RNA-seq library, $3 \mu \mathrm{g}$ of total RNA was used, and sequences were generated using an Illumina HiSeq 2500 platform (raw data available from the China National GeneBank under accession number CNP0000354 with the link https://db.cngb.org/search/project/ CNP0000354/). Sequence reads were aligned to the $M$. truncatula reference genome (IMGA version 4.0). The mapping rate of total reads in each sample was $>83 \%$. DEGs were filtered using the following criteria: fold change $>1.5, P<0.01$, and adjusted $P<0.05$. KOBAS (2.0) was used to identify enriched DEGs in Kyoto Encyclopedia of Genes and Genomes (KEGG) pathways, and the 20 most significantly credible pathways were selected.

RT-qPCR was used to confirm RNA-seq expression data for selected genes related to phytohormone biosynthesis and response as well as defense response genes. All primers used are listed in Supplemental Data Set 2. RNA was extracted with Trizol reagent (Invitrogen) from roots of cra2 and R108 treated with MtCEP1 peptides [synthesized with sequence AFQP(hyp)TTPGNSP(hyp)GVGH by GL Biochem] or inoculated with Sm1021 for $0,1,3$, and $5 \mathrm{~d}$. To test the expression of $M t Y U C 2$ in response to $\mathrm{N}$ starvation or MtCEP1, cra2 and R108 were grown in Fåhraeus medium supplemented with $10 \mathrm{mM} \mathrm{KNO}_{3}$ for $10 \mathrm{~d}$ and then transferred to Fåhraeus medium without $\mathrm{N}$ or to Fåhraeus medium (10 $\mathrm{mM} \mathrm{KNO}_{3}$ ) supplemented with $1 \mu \mathrm{M}$ MtCEP1 peptide for 2, 8, 12, and $24 \mathrm{~h}$.

First-strand cDNA was synthesized with $2.0 \mu \mathrm{g}$ of total RNA using MMLV reverse transcriptase (Promega, catalog no. M1701). SYBR Premix Ex-Taq (TaKaRa, catalog no. RR420A) was used as well as the CFX-96 realtime system (Bio-Rad). Gene expression was calculated using the $2^{-\Delta \Delta C T}$ method. MtACTIN11 was used as a reference gene (Gonzalez-Rizzo et al., 2006).

\section{Infection Threads, Primordia, and Nodulation Phenotyping Assays}

Plants were grown in a perlite:vermiculite $(2: 5, \mathrm{v} / \mathrm{v})$ mixture soaked in $\mathrm{N}$-deprived Fåhraeus medium for 1 week and then inoculated with Sm1021 for 3 weeks before the nodulation phenotype survey. To determine the infection thread and primordia phenotypes, plants were inoculated with Sm1021 carrying a ProHemA:LACZ fusion construct for $5 \mathrm{~d}$ before $\mathrm{X}-\mathrm{Gal}$ staining, which was performed as previously described by Gonzalez-Rizzo et al. (2006).

\section{Phosphoproteomics}

For qualitative and quantitative phosphoproteomics, germinated seedlings of cra2-8 and R108 were grown in Fahraeus medium (with $10 \mathrm{mM} \mathrm{KNO}_{3}$ ) for $12 \mathrm{~d}$ and then transferred to fresh medium with $1 \mu \mathrm{M}$ MtCEP1 peptides. Three independent pools of roots were harvested from plants treated with MtCEP1 peptides for $30 \mathrm{~min}$, and three independent pools of shoots were harvested from plants treated with MtCEP1 peptides for $6 \mathrm{~h}$. Total proteins were extracted from $1 \mathrm{~g}$ of roots or shoots with urea extraction buffer (150 mM Tris-HCl [pH 7.6], $8 \mathrm{M}$ urea, 0.5\% [w/v] SDS, 1.2\% [v/v] Triton X100, 20 mM EDTA, 20 mM EGTA, 1 mM phenylmethylsulfonyl fluoride, $5 \mathrm{mM} \mathrm{DTT}, 1 \%$ [v/v] phosphatase inhibitor mixture 2 [Roche], and $1 \%[\mathrm{v} / \mathrm{v}]$ EDTA-free protease-inhibitor mixture [Roche]), as previously reported by Guo and Li (2011) and Zhu et al. (2013). The protein supernatant was then precipitated using an acetone precipitation protocol (Yang et al., 2013). Afterward, $1 \mathrm{mg}$ of protein was quantified with a Bradford assay (Thermo Fisher Scientific) and digested via a filter-aided sample preparation. In brief, 
the protein pellet was dissolved in $8 \mathrm{M}$ urea, after which $10 \mathrm{mM}$ DTT was added for $1 \mathrm{~h}$ at $37^{\circ} \mathrm{C}$. lodoacetamide $(50 \mathrm{mM})$ was then added, and the solution was incubated for $30 \mathrm{~min}$ in darkness at room temperature. $\mathrm{NH}_{4}$ $\mathrm{HCO}_{3}$ water solution $(50 \mathrm{mM}$ ) was used afterward to replace the urea buffer in a 10-kD ultrafiltration tube three times. Trypsin (Promega, catalog no. V5280, MS grade) was dissolved in $200 \mu \mathrm{L}$ of $\mathrm{NH}_{4} \mathrm{HCO}_{3}(50 \mathrm{mM}$ water solution) at a dosage of $1: 50(\mathrm{w} / \mathrm{w})$ of the total protein to be digested, which was added to the ultrafiltration tube and digested overnight at $37^{\circ} \mathrm{C}$, after which peptides were harvested and lyophilized by a vacuum-freeze concentrator (Eppendorf).

$\mathrm{TiO}_{2}$ beads (Shimadzu, catalog no. 5010-21315) were used to enrich phosphopeptides following the protocol described in the "Phos-TiO Kit Instruction Manual" of Shimadzu. In brief, tryptic peptides were acidified with $0.1 \%(\mathrm{v} / \mathrm{v})$ trifluoroacetic acid/acetonitrile, flushed through a spin-tip device, and washed three times with $0.1 \%$ trifluoroacetic acid/acetonitrile, and phosphopeptides were eluted with a $5 \%(\mathrm{v} / \mathrm{v})$ ammonium hydroxide solution and lyophilized under vacuum at $4^{\circ} \mathrm{C}$.

For sequential window acquisition of all theoretical (SWATH)-MS, phosphopeptides were analyzed with a TripleTOF 5600 mass spectrometer (AB Sciex). Peptides enriched by $\mathrm{TiO}_{2}(1 \mu \mathrm{g}$ of digests) were loaded onto a self-packed C18 column $(75 \mu \mathrm{m} \times 15 \mathrm{~cm}$, Magic C18AQ $3 \mu \mathrm{m} 120 \AA \AA$, Dr. Maisch) with $98 \%$ mobile phase A ( $0.1 \%$ formic acid in water) and $2 \%$ mobile phase $B(0.1 \%$ formic acid in $98 \%$ acetonitrile) and eluted with the following 75 -min gradient: 0 to $0.5 \mathrm{~min}, 5$ to $8 \% \mathrm{~B} ; 0.5$ to $1 \mathrm{~min}, 8$ to $10 \% \mathrm{~B} ; 1$ to $50 \mathrm{~min}, 10$ to $22 \% \mathrm{~B} ; 50$ to $65 \mathrm{~min}, 22$ to $30 \% \mathrm{~B} ; 65$ to $70 \mathrm{~min}, 30$ to $80 \% \mathrm{~B}$; and 70 to $75 \mathrm{~min}, 80 \% \mathrm{~B}$. In the information-dependent acquisition (IDA) mode, the positive ion mode was GS1, 35 and GS2, 45; curtain gas, 25; ion spray voltage floating (ISVF), 2400 ; temperature, $150^{\circ} \mathrm{C}$; collision energy (CE), 5. The full scan was in the 350 to $1500 \mathrm{~m} / \mathrm{z}$ range with an accumulation time of $250 \mathrm{~ms}$, and the top 40 precursors were selected for MS-MS experiments using an accumulation time of $50 \mathrm{~ms}$. In the SWATH mode, a 250-ms full scan was performed with a 350 to $1500 \mathrm{~m} / \mathrm{z}$ range, followed by 50 SWATH scans in the 400 to $1000 \mathrm{~m} / \mathrm{z}$ range, and each fixed isolation window has a $14 \mathrm{~m} / \mathrm{z}$ width (with a window overlap of $1 \mathrm{~m} / \mathrm{z}$ ). The accumulation time for MS-MS was $80 \mathrm{~ms}$, and the CE setting principle was the same as for the IDA mode.

Raw IDA data acquired from the TripleTOF 5600 were analyzed with the ProteinPilot software (version 5.0, AB Sciex) with a Paragon algorithm search. Results were filtered with a $1 \%$ false discovery rate at both the protein and peptide levels, and the accuracy of the MS that we used was $0.05 \mathrm{D}$ for MS and 0.1 D for MS-MS fragment ions. The result file was imported into the PeakView SWATH MicroApp (version 2.0) software to generate a spectral library, with default parameters. The SWATH MicroApp was also used for peptide peak extraction from the SWATH data. Results were filtered with a $q<0.01$ threshold. MarkerView (version 1.3) was used for data normalization and the quantification of relative peptide or protein peak extraction data. The different proteins or peptides were selected with a fold change $>1.5$. The MS proteomics data have been deposited into the ProteomeXchange Consortium database via the PRIDE partner repository (Perez-Riverol et al., 2019), with the data set identifier PXD015995.

\section{Protein Interaction Assays}

For yeast two-hybrid assays, the kinase domain of CRA2 was cloned into a PGADT7 vector, and the C-terminal end (residues 521 to 1309) of MtEIN2 was cloned into PGBKT7. AD-CRA2 ${ }^{\mathrm{KD}}$ and BK-MtEIN2 ${ }^{\mathrm{CT}}$ were then transformed into an $\mathrm{AH} 109$ strain. The interaction was identified on a nutrient-defective medium (SD/-Ade/-His/-Leu/-Trp).

For GST pull-down assays, CRA2 ${ }^{\mathrm{KD}}$ was cloned into pGEX-4T-1 to generate a GST-CRA2 ${ }^{\mathrm{KD}}$ fusion construct. MtEIN2 ${ }^{\mathrm{CT}}$ (residues 459 to 1309 ) was then cloned into pET-30a as an MtEIN2 ${ }^{\mathrm{CT}}$-His fusion construct. Pairwise vectors (GST-CRA $2^{\mathrm{KD}}$ and MtEIN2 ${ }^{\mathrm{CT}}$-His; GST-CRA2 ${ }^{\mathrm{KD}}$ and $\mathrm{pET}$ 30a; pGEX-4T-1 and MtEIN2 ${ }^{\mathrm{CT}}$-His) were subsequently transferred into the
BL21 Escherichia coli strain. Glutathione Sepharose 4B agarose beads (GE Healthcare Life Science) were used to enrich GST-fused proteins and their interacting proteins. An immunoblot analysis involving anti-GST (Protein Tech, catalog no. 66001, lot no. $10005463,1: 5000$ dilution) and anti-His (Protein Tech, catalog no. 66005, lot no. 10004365, 1:5000 dilution) antibodies was then performed.

For firefly luciferase complementation imaging assays, the full-length CRA2 sequence was inserted into a pCAMBIA_nLUC vector, and MtEIN2 was fused with CLUC and then inserted into PCAMBIA_ccLUC. The plasmid was subsequently transformed into Nicotiana benthamiana leaves via $A$. tumefaciens infiltration, and the luciferase activity was analyzed as previously described by Bao et al. (2014).

\section{Subcellular Localization of CRA2 and MtEIN2}

For the subcellular localization of CRA2 and MtEIN2, full-length CRA2 or MtEIN2 protein was cloned into the PCAMBIA-1307-Pro35S:GFP vector, and then the Pro35S:CRA2-GFP or the Pro35S:EIN2-GFP vector was transiently coexpressed with a Pro35S:RFP-HDEL ER marker or a Pro35S:CBL1-RFP PM marker (Batistic et al., 2010) in N. benthamiana leaves using $A$. tumefaciens infiltration. For the colocalization of CRA2 and MtEIN2, MtEIN2 was cloned into the pCAMBIA-1307-Pro35S:RFP vector and cotransformed with the Pro35S:CRA2-GFP vector into $\mathrm{N}$. benthamiana leaves. The fluorescence was detected using an SP8 confocal microscope (Leica) at excitation and emission wavelengths of 488 and 495 to $545 \mathrm{~nm}$ for GFP and 552 and 590 to $670 \mathrm{~nm}$ for RFP.

\section{In Vitro Phosphorylation Assays}

The CRA2 kinase domain (1834-2898 bp) and the C-terminal domain of MtEIN2 (1375-3924 bp) were cloned into the pGEX4T-1 and pET30a vectors, respectively. GST-CRA2 $2^{\mathrm{KD}}$ and MtEIN2 ${ }^{\mathrm{CT}}$-His fusion proteins were expressed in the BL21 E. coli strain, Glutathione Sepharose 4B agarose beads (GE Healthcare Life Science) were used to purify the GSTCRA2 ${ }^{\mathrm{KD}}$ protein, and Ni-NTA agarose (Invitrogen, catalog no. R90115) was used to purify the MtEIN2 ${ }^{\mathrm{CT}}$-His protein. Purified proteins were then used as follows for in vitro phosphorylation assays.

To analyze the effects of different concentrations of $\mathrm{Mg}^{2+}$ and $\mathrm{Mn}^{2+}$ on the autophosphorylation activity of CRA2, $\sim 5 \mu \mathrm{g}$ of GST-CRA2 $2^{\mathrm{KD}}$ was incubated in a reaction buffer that contains $10 \mathrm{mM}$ HEPES (pH 7.4), $1 \mathrm{mM}$ $\mathrm{DTT}, 50 \mu \mathrm{M}$ ATP, $5 \mu \mathrm{Ci} / \mathrm{L}$ [ $\gamma^{-32}{ }^{32}$ ]ATP (China Isotope and Radiation), and 0 , 1,10 , or $50 \mathrm{mM} \mathrm{Mg}^{2+}$ or $\mathrm{Mn}^{2+}$ for $30 \mathrm{~min}$ at $37^{\circ} \mathrm{C}$. To assay the phosphorylation of MtEIN2 by CRA2, $0.5 \mu \mathrm{g}$ of GST-CRA2 ${ }^{\mathrm{KD}}$ and $5 \mu \mathrm{g}$ of MtEIN2 ${ }^{\mathrm{CT}}$-His were incubated in a reaction buffer that contains $10 \mathrm{mM}$ HEPES (pH 7.4), $1 \mathrm{mM}$ DTT, $50 \mu \mathrm{M}$ ATP, $5 \mu \mathrm{Ci} / \mathrm{L}$ [ $\gamma^{-32}{ }^{32}$ ]ATP, and $10 \mathrm{mM}$ $\mathrm{Mg}^{2+}$ or $\mathrm{Mn}^{2+}$ for $30 \mathrm{~min}$ at $37^{\circ} \mathrm{C}$. The reaction was stopped by the addition of a $5 \times$ SDS loading buffer. Samples were then separated through $10 \%$ (w/ v) SDS-PAGE, and Coomassie Brilliant Blue staining was used to visualize the protein loading. A storage phosphor screen (Amersham Biosciences) was used to harvest the radioactive signal, which was imaged with a Typhoon 9410 device (GE Healthcare).

\section{Phos-Tag Assays}

cra2/Pro35S:MtCRA2-FLAG-HA plants were grown in Fahraeus medium supplemented with $10 \mathrm{mM} \mathrm{NO}_{3}{ }^{-}$for $10 \mathrm{~d}$ and then transferred to the same medium supplemented also with $1 \mu \mathrm{M}$ MtCEP 1 for $0,0.5,2,6,12$, and $24 \mathrm{~h}$; CEP1 peptides were incorporated into the agar, so shoots were not extensively in contact with peptides. Proteins were then extracted from three independent pools of roots and shoots with a lysing buffer $(10 \mathrm{mM} \mathrm{Tris}-\mathrm{HCl}$, $\mathrm{pH} 7.4,5 \mathrm{mM}$ EDTA, $150 \mathrm{mM} \mathrm{NaCl}, 10 \%$ glycerin, 1\% [v/v] Triton X-100, $1 \mathrm{mM}$ phenylmethylsulfonyl fluoride, $5 \mathrm{mM}$ DTT, $1 \%$ [v/v] phosphatase inhibitor mixture 2 [Roche], and 1\% [v/v] EDTA-free protease-inhibitor 
mixture [Roche]). Total proteins were concentrated with a 10-kD filter (Millipore), and proteins were then quantified with a Bradford assay (Thermo-Fisher). For the CIAP treatment, proteins were extracted with the same buffer but without the phosphatase inhibitor mixture from roots and shoots of cra2/Pro35S:CRA2-FLAG-HA plants that were not treated with MtCEP1, after which the proteins were incubated with CIAP for 30 min at $37^{\circ} \mathrm{C}$. About $100 \mu \mathrm{g}$ of protein treated with or without CIAP was subjected to a separation via $10 \%$ (w/v) SDS-PAGE with $100 \mu$ M Phos-tag (Boppard, catalog no. 304-93521). $\mathrm{Mn}^{2+}$-Phos-tag SDS-PAGE preparation and immunoblotting were performed based on the protocol described in FUJIFILM Wako Chemicals' Phos-tag guide book (https://labchem-wako. fujifilm.com/us/category/lifescience/proteomics/phostag/index.html). Proteins $(10 \mu \mathrm{g})$ were assayed using another $10 \%(\mathrm{w} / \mathrm{v})$ SDS-PAGE gel as a reference, and $\mathrm{HA}$ antibodies (Sigma-Aldrich, catalog no. H3663, lot no. 066M4837V) or $\beta$-actin (CWBio, catalog no. CW0264) antibodies were used for the immunoblot analysis. The intensity of immunoblot bands was assayed with ImageJ software (https://imagej.nih.gov/ij).

\section{Cleavage Assay of MtEIN2}

For the cleavage assay of MtEIN2, the full-length CDS was cloned into the pCAMBIA_2301-Pro35S:HA/Pro35S:GUS vector. Then, Pro35S:MtEIN2HA/Pro35S:GUS was transformed into R108 or cra2 using A. rhizogenes based on hairy root transformation. To assess the effect of ACC on the cleavage of MtEIN2, composite plants with transgenic roots (21 d old) grown in half-strength Murashige and Skoog medium (without Suc) were treated with 0,5 , or $50 \mu \mathrm{M} \mathrm{ACC}$ for $24 \mathrm{~h}$. For $\mathrm{N}$ starvation and MtCEP1 peptide treatments, composite plants with transgenic roots (21 d old) grown in half-strength Murashige and Skoog medium (without Suc) were transferred to Fåhraeus medium with or without $\mathrm{NO}_{3}{ }^{-}(10 \mathrm{mM})$ or $\mathrm{NO}_{3}{ }^{-}(10$ $\mathrm{mM}$ ) with MtCEP1 peptides $(1 \mu \mathrm{M})$ for $24 \mathrm{~h}$, and total proteins were then extracted from roots. For the immunoblot analysis, a 1:10,000 dilution of an anti-HA antibody (Sigma-Aldrich, catalog no. H3663, lot no. 066M4837V) was used to identify full-length MtEIN2-HA and C-terminal fragments and a 1:10,000 anti-GUS (Sigma-Aldrich, catalog no. G5420, lot no. 037M4771V) antibody dilution was used as an internal reference to quantify the GUS control pool.

\section{Quantification of Acropetal Polar Auxin Transport}

Four-day-old R108 and cra2 plants grown on Fåhraeus medium were used for the quantification of acropetal polar auxin transport. [ $\left.{ }^{3} \mathrm{H}\right] \mathrm{IAA}(7.5 \mu \mathrm{L}$ at 1 $\mathrm{mCi} / \mathrm{mL}$ ) was mixed with $1.5 \mathrm{~mL}$ of $1 \%$ agarose (Bacto). Once solid, the agar was cut into $2 \times 2 \times 2 \mathrm{~mm}^{3}$ "donor blocks," and a 2-cm-long root segment was cut off from the root tips. Roots were laid on plates containing Fåhraeus medium, with the basipetal (cut) end in contact with a donor block and separated from the medium by Parafilm and then placed vertically and covered with aluminum foil for $6 \mathrm{~h}$. A $0.5-\mathrm{cm}$ segment was cut from the basal end, and the tip of the root was removed. Only the middle segment was placed into a 4-mL vial filled with scintillation fluid (Perkin-Elmer, catalog number 1200.437) and shaken on a shaker (150 rpm/min) overnight. The radioactivity was then counted in a Hidex $300 \mathrm{SL}$ scintillation counter.

\section{DR5:GUS Staining Assays and the Influence of $\mathrm{N}$ on RSA}

The DR5 element, cloned from a DR5:GFP construct (Zhou et al., 2013), was fused with a $35 \mathrm{~S}$ minimal promoter and then cloned into a pCAMBIA_1381 vector. The DR5:GUS vector was stably transformed into R108 and cra2-8. For the GUS staining, R108/DR5:GUS and cra2/DR5:GUS plants were grown in a modified hydroponic nutrient solution from the Medicago truncatula handbook (https://www.noble.org/globalassets/ docs/medicago-handbook/growing-medicago-truncatula.pdf; basal medium: $0.5 \mathrm{mM} \mathrm{KH}_{2} \mathrm{PO}_{4}, 1 \mathrm{mM} \mathrm{MgSO}{ }_{4} \cdot 7 \mathrm{H}_{2} \mathrm{O}, 0.25 \mathrm{mM} \mathrm{CaCl}, 100 \mu \mathrm{M}$
Fe-Na-EDTA, $0.25 \mathrm{mM} \mathrm{K}_{2} \mathrm{SO}_{4}, 30 \mu \mathrm{M} \mathrm{H}_{3} \mathrm{BO}_{3}, 5 \mu \mathrm{M} \mathrm{MnSO}_{4}, 1 \mu \mathrm{M} \mathrm{ZnSO}_{4}$,

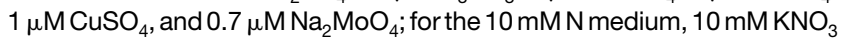
was added; for the $0.25 \mathrm{mM} \mathrm{N}$ medium, $9.75 \mathrm{mM} \mathrm{KCl}$ and $0.25 \mathrm{mM} \mathrm{KNO}_{3}$ were added) for $10 \mathrm{~d}$ in a 24-cm:18-cm:16-cm (length:width:height) vessel. Two days after seedling germination, an air pump was used to aerate the liquid medium with a flow of $2 \mathrm{~L} / \mathrm{min}$. GUS staining, as described previously by Herrbach et al. (2014), was performed for 2 to $3 \mathrm{~h}$. Tissues were subsequently imaged using an Olympus microscope (BX51) with an interference device.

To assess the effect of nitrogen on RSA, the seedlings were grown in medium with various $\mathrm{NO}_{3}{ }^{-}$and $\mathrm{NH}_{4}{ }^{+}$concentrations, as in the DR5:GUS assay, for $12 \mathrm{~d}$. As 2.5 or $10 \mathrm{mM} \mathrm{NH}_{4}{ }^{+}$induced a slight toxicity in some plants, the plants with severe damage were excluded when we quantified the lateral root number and root length phenotypes.

\section{Free IAA Content Quantification}

Germinated seedlings were grown in the modified hydroponic nutrient solution described above with or without $\mathrm{KNO}_{3}(10 \mathrm{mM})$ for $7 \mathrm{~d}$. Roots were cut off at the root-shoot junction, and three independent pools of tissue from different plants of the same genotype were harvested.

IAA was extracted and purified as previously described by Wang et al. (2015) from R108 and cra2T-4. Root samples ( $150 \mathrm{mg})$ were homogenized and extracted in $80 \%$ methanol for $24 \mathrm{~h}$, and $\left[{ }^{2} \mathrm{H}_{2}\right] \mathrm{IAA}$ was used as an internal standard. The purification was achieved with Oasis Max solidphase extract cartridges (Waters). The liquid chromatography-MS-MS analysis was performed on a UPLC system (Waters) coupled to the 6500 Q-Trap system (AB Sciex). A BEH C18 column $(1.7 \mathrm{~mm}, 2.1 \times 50 \mathrm{~mm}$, Waters) was used, and the mobile phase of $0.05 \%(\mathrm{v} / \mathrm{v}) \mathrm{HAc}\left(\mathrm{CH}_{3} \mathrm{COOH} ; \mathrm{A}\right)$ and $0.05 \%(\mathrm{v} / \mathrm{v}) \mathrm{HAc}$ in acetonitrile $(\mathrm{B})$ was used with the following gradient: initial stage, mobile phase $B$ was increased from 5 to $70 \%$ within $6 \mathrm{~min}$. The IAA quantification was performed in the multiple reaction monitoring mode, and the selected multiple reaction monitoring transition for $\left[{ }^{2} \mathrm{H}_{2}\right] \mathrm{IAA}$ was $176.0>132.0$ and that for IAA was $174.0>130.0$.

\section{Statistical Analysis}

For root architecture and symbiotic nodulation phenotype assays, gene expression analysis, and the quantification of intensity of immunoblot bands, statistical analysis was performed as described in the figure legends. Significant differences were determined with paired two-tailed Student's $t$ test using Excel 2016 or with ANOVA and Kruskal-Wallis nonparametric testing using IBM SPSS Statistics version 25 (Supplemental Data Set 3).

\section{Accession Numbers}

Sequence data of the $M$. truncatula genes studied in this article can be found in Legumeinfo (https://legumeinfo.org/search/gene) under the following accession numbers: MtCRA2 (Medtr3g110840), MtEIN2 (Medtr0041s0030), and MtYUC2 (Medtr6g086870).

\section{Supplemental Data}

Supplemental Figure 1. Schematic diagram and sequence of cra2 mutants.

Supplemental Figure 2. Transcriptome analysis of the cra2 mutant.

Supplemental Figure 3. RNA-seq expression heatmaps of selected genes related to nod factor signaling, $\mathrm{NO}_{3}{ }^{-}$transporters and reductases.

Supplemental Figure 4. Expression of MtYUC genes in roots and shoots of the cra2 mutant. 
Supplemental Figure 5. Effect of MtCRA2 on auxin transport and of NPA on root phenotypes of the cra2 mutant.

Supplemental Figure 6. Auxin accumulation is not the main cause of the low nodulation phenotype of the cra2 mutant.

Supplemental Figure 7. YUC inhibitors cannot rescue the low nodulation phenotype of the cra2 mutant.

Supplemental Figure 8. TIBA cannot rescue the insensitivity of the cra2 mutant to rhizobia.

Supplemental Figure 9. Representative sequences of the MtYUC2 target site 2 used to generate the yuc2 $C$ and cra2 yuc2C mutants.

Supplemental Figure 10. Expression of MtCEP1 in the roots of R108.

Supplemental Figure 11. Sequence of the ein2 $C$ and cra2 ein2C mutants generated by CRISPR/Cas9 and partial rescue of the compact root architecture phenotype of the cra2 mutant by an MtEIN2 mutation.

Supplemental Figure 12. Expression of MtYUC2 in roots of the Mtein2C mutant.

Supplemental Figure 13. Overexpression of MtCRA2 rescues the phenotype of the cra2 mutant.

Supplemental Figure 14. Quantitative extracted ion chromatograms of MtEIN2 phosphopeptides containing Ser643 in R108 and cra2 mutant.

Supplemental Figure 15. MS-MS spectra of MtEIN2 phosphorylated peptides containing the Ser ${ }^{643}$ and Ser ${ }^{924}$ phosphorylated sites.

Supplemental Figure 16. Pearson's correlation ( $r$ ) values and scatterplots of subcellular colocalization experiments.

Supplemental Figure 17. Effect of an ACC treatment on the cleavage of MtEIN2 in cra2 mutant roots.

Supplemental Figure 18. The generation of R108/cra2C, R108/ein2C composite plants with wild type shoots and mutant roots by CRISPR/ Cas9.

Supplemental Data Set 1. Phosphopeptides identified by a quantitative phosphoproteomic approach as downregulated in the cra2 mutant.

Supplemental Data Set 2. List of primers used in this article.

Supplemental Data Set 3. Statistical analysis data.

\section{ACKNOWLEDGMENTS}

We thank Peibin Qin and Yinghua Zhao (Shanghai AB Sciex Analytical Instrument Trading Co.) for help with MS analyses, Jijun Yan and Jinfang Chu (Institute of Genetics and Developmental Biology, Chinese Academy of Sciences) for help with the IAA quantification, Chuanen Zhou (School of Life Sciences, Shandong University) for providing the DR5:GUS vector, and Qijun Chen (College of Biological Science, China Agriculture University) for providing the CRISPR/Cas9 system. This work was supported by the National Natural Science Foundation of China (grants 31772658 and 31571587), the project for Extramural Scientists of the State Key Laboratory of Agrobiotechnology, China Agricultural University (grant 2018SKLAB6-22), and the China Postdoctoral Science Foundation (grant 2019M660878).

\section{AUTHOR CONTRIBUTIONS}

T.W. and J.D. designed the research; F.Z. performed the main experiments and data analysis, helped by J.D., H.C., P.L., L.Z., Q.Y., R.L., and M.B.; J.W. provided Tnt1 insertional mutants; F.Z., J.D., T.W., and F.F. wrote the article.
Received November 22, 2019; revised June 3, 2020; accepted June 24 , 2020; published June 25, 2020.

\section{REFERENCES}

Araya, T., Miyamoto, M., Wibowo, J., Suzuki, A., Kojima, S., Tsuchiya, Y.N., Sawa, S., Fukuda, H., von Wirén, N., and Takahashi, H. (2014). CLE-CLAVATA1 peptide-receptor signaling module regulates the expansion of plant root systems in a nitrogendependent manner. Proc. Natl. Acad. Sci. USA 111: 2029-2034.

Bao, F., Huang, X., Zhu, C., Zhang, X., Li, X., and Yang, S. (2014). Arabidopsis HSP90 protein modulates RPP4-mediated temperaturedependent cell death and defense responses. New Phytol. 202: 1320-1334.

Batistic, O., Waadt, R., Steinhorst, L., Held, K., and Kudla, J. (2010). CBL-mediated targeting of CIPKs facilitates the decoding of calcium signals emanating from distinct cellular stores. Plant J. 61: 211-222.

Chapman, K., Ivanovici, A., Taleski, M., Sturrock, C.J., Ng, J.L.P., Mohd-Radzman, N.A., Frugier, F., Bennett, M.J., Mathesius, U., and Djordjevic, M.A. (2020). CEP receptor signalling controls root system architecture in Arabidopsis and Medicago. New Phytol. 226: 1809-1821.

Crook, A.D., Schnabel, E.L., and Frugoli, J.A. (2016). The systemic nodule number regulation kinase SUNN in Medicago truncatula interacts with MtCLV2 and MtCRN. Plant J. 88: 108-119.

Desbrosses, G.J., and Stougaard, J. (2011). Root nodulation: A paradigm for how plant-microbe symbiosis influences host developmental pathways. Cell Host Microbe 10: 348-358.

Djordjevic, M.A., Mohd-Radzman, N.A., and Imin, N. (2015). Smallpeptide signals that control root nodule number, development, and symbiosis. J. Exp. Bot. 66: 5171-5181.

Forde, B.G. (2014). Nitrogen signalling pathways shaping root system architecture: An update. Curr. Opin. Plant Biol. 21: 30-36.

Franssen, H.J., Xiao, T.T., Kulikova, O., Wan, X., Bisseling, T., Scheres, B., and Heidstra, R. (2015). Root developmental programs shape the Medicago truncatula nodule meristem. Development 142: 2941-2950.

Gamas, P., Brault, M., Jardinaud, M.F., and Frugier, F. (2017). Cytokinins in symbiotic nodulation: When, where, what for? Trends Plant Sci. 22: 792-802.

Gautrat, P., Laffont, C., and Frugier, F. (2020). Compact Root Architecture 2 promotes root competence for nodulation through the miR2111 systemic effector. Curr. Biol. 30: 1339-1345.

Gonzalez-Rizzo, S., Crespi, M., and Frugier, F. (2006). The Medicago truncatula CRE1 cytokinin receptor regulates lateral root development and early symbiotic interaction with Sinorhizobium meliloti. Plant Cell 18: 2680-2693.

Gou, L., Zhang, R., Ma, L., Zhu, F., Dong, J., and Wang, T. (2016). Multigene synergism increases the isoflavone and proanthocyanidin contents of Medicago truncatula. Plant Biotechnol. J. 14: 915-925.

Guo, G., and Li, N. (2011). Relative and accurate measurement of protein abundance using $15 \mathrm{~N}$ stable isotope labeling in Arabidopsis (SILIA). Phytochemistry 72: 1028-1039.

Guo, Y., Han, L., Hymes, M., Denver, R., and Clark, S.E. (2010). CLAVATA2 forms a distinct CLE-binding receptor complex regulating Arabidopsis stem cell specification. Plant J. 63: 889-900.

Herrbach, V., Remblière, C., Gough, C., and Bensmihen, S. (2014). Lateral root formation and patterning in Medicago truncatula. J. Plant Physiol. 171: 301-310.

Hiltenbrand, R., Thomas, J., McCarthy, H., Dykema, K.J., Spurr, A., Newhart, H., Winn, M.E., and Mukherjee, A. (2016). A 
developmental and molecular view of formation of auxin-induced nodule-like structures in land plants. Front. Plant Sci. 7: 1692.

Huault, E., Laffont, C., Wen, J., Mysore, K.S., Ratet, P., Duc, G., and Frugier, F. (2014). Local and systemic regulation of plant root system architecture and symbiotic nodulation by a receptor-like kinase. PLoS Genet. 10: e1004891.

Huo, X., Schnabel, E., Hughes, K., and Frugoli, J. (2006). RNAi phenotypes and the localization of a protein:GUS fusion imply a role for Medicago truncatula PIN genes in nodulation. J. Plant Growth Regul. 25: 156-165.

Imin, N., Mohd-Radzman, N.A., Ogilvie, H.A., and Djordjevic, M.A. (2013). The peptide-encoding CEP1 gene modulates lateral root and nodule numbers in Medicago truncatula. J. Exp. Bot. 64: 5395-5409.

Jin, J., Watt, M., and Mathesius, U. (2012). The autoregulation gene SUNN mediates changes in root organ formation in response to nitrogen through alteration of shoot-to-root auxin transport. Plant Physiol. 159: 489-500.

Ju, C., et al. (2012). CTR1 phosphorylates the central regulator EIN2 to control ethylene hormone signaling from the ER membrane to the nucleus in Arabidopsis. Proc. Natl. Acad. Sci. USA 109: 19486-19491.

Kakei, Y., Yamazaki, C., Suzuki, M., Nakamura, A., Sato, A., Ishida, Y., Kikuchi, R., Higashi, S., Kokudo, Y., Ishii, T., Soeno, K., and Shimada, Y. (2015). Small-molecule auxin inhibitors that target YUCCA are powerful tools for studying auxin function. Plant J. 84: 827-837.

Krusell, L., et al. (2011). The Clavata2 genes of pea and Lotus japonicus affect autoregulation of nodulation. Plant J. 65: 861-871.

Laffont, C., Blanchet, S., Lapierre, C., Brocard, L., Ratet, P., Crespi, M., Mathesius, U., and Frugier, F. (2010). The compact root architecture1 gene regulates lignification, flavonoid production, and polar auxin transport in Medicago truncatula. Plant Physiol. 153: $1597-1607$

Laffont, C., Huault, E., Gautrat, P., Endre, G., Kalo, P., Bourion, V., Duc, G., and Frugier, F. (2019). Independent regulation of symbiotic nodulation by the SUNN negative and CRA2 positive systemic pathways. Plant Physiol. 180: 559-570.

Larrainzar, E., et al. (2015). Deep sequencing of the Medicago truncatula root transcriptome reveals a massive and early interaction between nodulation factor and ethylene signals. Plant Physiol. 169: 233-265.

Li, C., et al. (2015). Glycosylphosphatidylinositol-anchored proteins as chaperones and co-receptors for FERONIA receptor kinase signaling in Arabidopsis. eLife 4: 512-524.

Liu, H., Zhang, C., Yang, J., Yu, N., and Wang, E. (2018). Hormone modulation of legume-rhizobial symbiosis. J. Integr. Plant Biol. 60: 632-648.

Ma, L., Zhu, F., Li, Z., Zhang, J., Li, X., Dong, J., and Wang, T. (2015). TALEN-based mutagenesis of lipoxygenase LOX3 enhances the storage tolerance of rice (Oryza sativa) seeds. PLoS One 10: e0143877.

Ma, W., Li, J., Qu, B., He, X., Zhao, X., Li, B., Fu, X., and Tong, Y. (2014). Auxin biosynthetic gene TAR2 is involved in low nitrogenmediated reprogramming of root architecture in Arabidopsis. Plant J. 78: 70-79.

Maekawa-Yoshikawa, M., Müller, J., Takeda, N., Maekawa, T., Sato, S., Tabata, S., Perry, J., Wang, T.L., Groth, M., Brachmann, A., and Parniske, M. (2009). The temperature-sensitive brush mutant of the legume Lotus japonicus reveals a link between root development and nodule infection by rhizobia. Plant Physiol. 149: $1785-1796$.

Miao, Z.Q., Zhao, P.X., Mao, J., Yu, L., Yuan, Y., Tang, H., Liu, Z.B., and Xiang, C. (2018). HOMEOBOX PROTEIN52 mediates the crosstalk between ethylene and auxin signaling during primary root elongation by modulating auxin transport-related gene expression. Plant Cell 30: 2761-2778.

Mohd-Radzman, N.A., Binos, S., Truong, T.T., Imin, N., Mariani, M., and Djordjevic, M.A. (2015). Novel MtCEP1 peptides produced in vivo differentially regulate root development in Medicago truncatula. J. Exp. Bot. 66: 5289-5300.

Mohd-Radzman, N.A., Djordjevic, M.A., and Imin, N. (2013). Nitrogen modulation of legume root architecture signaling pathways involves phytohormones and small regulatory molecules. Front. Plant Sci. 4: 385 .

Mohd-Radzman, N.A., Laffont, C., Ivanovici, A., Patel, N., Reid, D., Stougaard, J., Frugier, F., Imin, N., and Djordjevic, M.A. (2016). Different pathways act downstream of the CEP peptide receptor CRA2 to regulate lateral root and nodule development. Plant Physiol. 171: 2536-2548.

Ng, J.L., Hassan, S., Truong, T.T., Hocart, C.H., Laffont, C., Frugier, F., and Mathesius, U. (2015). Flavonoids and auxin transport inhibitors rescue symbiotic nodulation in the Medicago truncatula cytokinin perception mutant cre1. Plant Cell 27: 2210-2226.

Ohkubo, Y., Tanaka, M., Tabata, R., Ogawa-Ohnishi, M., and Matsubayashi, Y. (2017). Shoot-to-root mobile polypeptides involved in systemic regulation of nitrogen acquisition. Nat. Plants 3: 17029.

Okamoto, S., Ohnishi, E., Sato, S., Takahashi, H., Nakazono, M., Tabata, S., and Kawaguchi, M. (2009). Nod factor/nitrate-induced CLE genes that drive HAR1-mediated systemic regulation of nodulation. Plant Cell Physiol. 50: 67-77.

Oldroyd, G.E., Engstrom, E.M., and Long, S.R. (2001). Ethylene inhibits the Nod factor signal transduction pathway of Medicago truncatula. Plant Cell 13: 1835-1849.

Oldroyd, G.E., Murray, J.D., Poole, P.S., and Downie, J.A. (2011). The rules of engagement in the legume-rhizobial symbiosis. Annu. Rev. Genet. 45: 119-144.

Ota, R., Ohkubo, Y., Yamashita, Y., Ogawa-Ohnishi, M., and Matsubayashi, Y. (2020). Shoot-to-root mobile CEPD-like 2 integrates shoot nitrogen status to systemically regulate nitrate uptake in Arabidopsis. Nat. Commun. 11: 641.

Patel, N., et al. (2018). Diverse peptide hormones affecting root growth identified in the Medicago truncatula secreted peptidome. Mol. Cell. Proteomics 17: 160-174.

Pellizzaro, A., Alibert, B., Planchet, E., Limami, A.M., and Morère-Le Paven, M.C. (2017). Nitrate transporters: An overview in legumes. Planta 246: 585-595.

Penmetsa, R.V., and Cook, D.R. (1997). A legume ethyleneinsensitive mutant hyperinfected by its rhizobial symbiont. Science 275: 527-530.

Penmetsa, R.V., Frugoli, J.A., Smith, L.S., Long, S.R., and Cook, D.R. (2003). Dual genetic pathways controlling nodule number in Medicago truncatula. Plant Physiol. 131: 998-1008.

Penmetsa, R.V., et al. (2008). The Medicago truncatula ortholog of Arabidopsis EIN2, sickle, is a negative regulator of symbiotic and pathogenic microbial associations. Plant J. 55: 580-595.

Perez-Riverol, Y., et al. (2019). The PRIDE database and related tools and resources in 2019: Improving support for quantification data. Nucleic Acids Res. 47: D442-D450.

Pislariu, C.I., et al. (2012). A Medicago truncatula tobacco retrotransposon insertion mutant collection with defects in nodule development and symbiotic nitrogen fixation. Plant Physiol. 159: 1686-1699.

Prayitno, J., Rolfe, B.G., and Mathesius, U. (2006). The ethyleneinsensitive sickle mutant of Medicago truncatula shows altered 
auxin transport regulation during nodulation. Plant Physiol. 142: 168-180.

Reid, D., Liu, H., Kelly, S., Kawaharada, Y., Mun, T., Andersen, S.U., Desbrosses, G., and Stougaard, J. (2018). Dynamics of ethylene production in response to compatible Nod factor. Plant Physiol. 176: 1764-1772.

Roy, S., et al. (2017). MtLAX2, a functional homologue of the Arabidopsis auxin influx transporter AUX1, is required for nodule organogenesis. Plant Physiol. 174: 326-338.

Sasaki, T., Suzaki, T., Soyano, T., Kojima, M., Sakakibara, H., and Kawaguchi, M. (2014). Shoot-derived cytokinins systemically regulate root nodulation. Nat. Commun. 5: 4983.

Schiessl, K., et al. (2019). NODULE INCEPTION recruits the lateral root developmental program for symbiotic nodule organogenesis in Medicago truncatula. Curr. Biol. 29: 3657-3668.e5.

Shabala, S., White, R.G., Djordjevic, M.A., Ruan, Y.L., and Mathesius, U. (2016). Root-to-shoot signalling: Integration of diverse molecules, pathways and functions. Funct. Plant Biol. 43: 87-104.

Soyano, T., Shimoda, Y., Kawaguchi, M., and Hayashi, M. (2019). A shared gene drives lateral root development and root nodule symbiosis pathways in Lotus. Science 366: 1021-1023.

Tabata, R., Sumida, K., Yoshii, T., Ohyama, K., Shinohara, H., and Matsubayashi, Y. (2014). Perception of root-derived peptides by shoot LRR-RKs mediates systemic N-demand signaling. Science 346: 343-346.

Tsikou, D., Yan, Z., Holt, D.B., Abel, N.B., Reid, D.E., Madsen, L.H., Bhasin, H., Sexauer, M., Stougaard, J., and Markmann, K. (2018). Systemic control of legume susceptibility to rhizobial infection by a mobile microRNA. Science 362: 233-236.

Wang, B., Chu, J., Yu, T., Xu, Q., Sun, X., Yuan, J., Xiong, G., Wang, G., Wang, Y., and Li, J. (2015). Tryptophan-independent auxin biosynthesis contributes to early embryogenesis in Arabidopsis. Proc. Natl. Acad. Sci. USA 112: 4821-4826.

Wang, Y., Yang, W., Zuo, Y., Zhu, L., Hastwell, A.H., Chen, L., Tian, Y., Su, C., Ferguson, B.J., and Li, X. (2019). GmYUC2a mediates auxin biosynthesis during root development and nodulation in soybean. J. Exp. Bot. 70: 3165-3176.
Wen, X., Zhang, C., Ji, Y., Zhao, Q., He, W., An, F., Jiang, L., and Guo, H. (2012). Activation of ethylene signaling is mediated by nuclear translocation of the cleaved EIN2 carboxyl terminus. Cell Res. 22: 1613-1616.

Xing, H.L., Dong, L., Wang, Z.P., Zhang, H.Y., Han, C.Y., Liu, B., Wang, X.C., and Chen, Q.J. (2014). A CRISPR/Cas9 toolkit for multiplex genome editing in plants. BMC Plant Biol. 14: 327.

Xu, G., Fan, X., and Miller, A.J. (2012). Plant nitrogen assimilation and use efficiency. Annu. Rev. Plant Biol. 63: 153-182.

Yang, Z., Guo, G., Zhang, M., Liu, C.Y., Hu, Q., Lam, H., Cheng, H., Xue, Y., Li, J., and Li, N. (2013). Stable isotope metabolic labelingbased quantitative phosphoproteomic analysis of Arabidopsis mutants reveals ethylene-regulated time-dependent phosphoproteins and putative substrates of constitutive triple response 1 kinase. Mol. Cell. Proteomics 12: 3559-3582.

Yendrek, C.R., et al. (2010). A putative transporter is essential for integrating nutrient and hormone signaling with lateral root growth and nodule development in Medicago truncatula. Plant J. 62: 100-112.

Yu, L.H., Miao, Z.Q., Qi, G.F., Wu, J., Cai, X.T., Mao, J.L., and Xiang, C.B. (2014). MADS-box transcription factor AGL21 regulates lateral root development and responds to multiple external and physiological signals. Mol. Plant 7: 1653-1669.

Zhou, C., et al. (2013). The trans-acting short interfering RNA3 pathway and no apical meristem antagonistically regulate leaf margin development and lateral organ separation, as revealed by analysis of an argonaute7/lobed leaflet1 mutant in Medicago truncatula. Plant Cell 25: 4845-4862.

Zhou, H., Lin, H., Chen, S., Becker, K., Yang, Y., Zhao, J., Kudla, J., Schumaker, K.S., and Guo, Y. (2014). Inhibition of the Arabidopsis salt overly sensitive pathway by 14-3-3 proteins. Plant Cell 26: 1166-1182.

Zhu, L., Liu, D., Li, Y., and Li, N. (2013). Functional phosphoproteomic analysis reveals that a serine-62-phosphorylated isoform of ethylene response factor110 is involved in Arabidopsis bolting. Plant Physiol. 161: 904-917. 
A CEP Peptide Receptor-Like Kinase Regulates Auxin Biosynthesis and Ethylene Signaling to Coordinate Root Growth and Symbiotic Nodulation in Medicago truncatula

Fugui Zhu, Jie Deng, Hong Chen, Peng Liu, Lihua Zheng, Qinyi Ye, Rui Li, Mathias Brault, Jiangqi Wen, Florian Frugier, Jiangli Dong and Tao Wang

Plant Cell 2020;32;2855-2877; originally published online June 25, 2020;

DOI 10.1105/tpc.19.00428

This information is current as of December 16, 2020

Supplemental Data

References

Permissions

eTOCs

CiteTrack Alerts

Subscription Information

\section{/content/suppl/2020/07/02/tpc.19.00428.DC1.html}

This article cites 69 articles, 28 of which can be accessed free at: /content/32/9/2855.full.html\#ref-list-1

https://www.copyright.com/ccc/openurl.do?sid=pd_hw1532298X\&issn=1532298X\&WT.mc_id=pd_hw1532298X

Sign up for eTOCs at:

http://www.plantcell.org/cgi/alerts/ctmain

Sign up for CiteTrack Alerts at:

http://www.plantcell.org/cgi/alerts/ctmain

Subscription Information for The Plant Cell and Plant Physiology is available at: http://www.aspb.org/publications/subscriptions.cfm 